\title{
Effectiveness and adequacy of blinding in the moderation of pain outcomes: Systematic review and meta-analyses of dry needling trials
}

\author{
Felicity A Braithwaite ${ }^{\text {Corresp., }}{ }_{1,2}$, Julie L Walters $^{1}{ }^{\text {, }}$ Lok Sze Katrina Li ${ }^{1}{ }^{\text {, }}$ G. Lorimer Moseley ${ }^{1,2}$, Marie T \\ Williams ${ }^{1,3}$, Maureen P McEvoy ${ }^{1}$ \\ ${ }^{1}$ School of Health Sciences, University of South Australia, Adelaide, Australia \\ 2 Body in Mind research group, University of South Australia, Adelaide, Australia \\ 3 Alliance for Research in Exercise, Nutrition and Activity (ARENA), University of South Australia, Adelaide, Australia \\ Corresponding Author: Felicity A Braithwaite \\ Email address: felicity.braithwaite@gmail.com
}

Background: Blinding is critical to clinical trials because it allows for separation of specific intervention effects from bias, by equalising all factors between groups except for the proposed mechanism of action. Absent or inadequate blinding in clinical trials has consistently been shown in large meta-analyses to result in overestimation of intervention effects. Blinding in dry needling trials, particularly blinding of participants and therapists, is a practical challenge; therefore, specific effects of dry needling have yet to be determined. Despite this, dry needling is widely used by health practitioners internationally for the treatment of pain. This review presents the first empirical account of the influence of blinding on intervention effect estimates in dry needling trials. The aim of this systematic review was to determine whether participant beliefs about group allocation relative to actual allocation (blinding effectiveness), and/or adequacy of blinding procedures, moderated pain outcomes in dry needling trials. Methods: Twelve databases (MEDLINE, EMBASE, AMED, Scopus, CINAHL, PEDro, The Cochrane Library, Trove, ProQuest, trial registries) were searched from inception to February 2016. Trials that compared active dry needling with a sham that simulated dry needling were included. Two independent reviewers performed screening, data extraction, and critical appraisal. Available blinding effectiveness data were converted to a blinding index, a quantitative measurement of blinding, and meta-regression was used to investigate the influence of the blinding index on pain. Adequacy of blinding procedures was based on critical appraisal, and subgroup meta-analyses were used to investigate the influence of blinding adequacy on pain. Metaanalytical techniques used inverse-variance random-effects models. Results: The search identified 4894 individual publications with 24 eligible for inclusion in the quantitative syntheses. In 19 trials risk of methodological bias was high or unclear. Five trials were adequately blinded, and blinding was assessed and sufficiently reported to compute the 
blinding index in 10 trials. There was no evidence of a moderating effect of blinding index on pain. For short-term and long-term pain assessments pooled effects for inadequately blinded trials were statistically significant in favour of active dry needling, whereas there was no evidence of a difference between active and sham groups for adequately blinded trials. Discussion: The small number and size of included trials meant there was insufficient evidence to conclusively determine if a moderating effect of blinding effectiveness or adequacy existed. However, with the caveats of small sample size, generally unclear risk of bias, statistical heterogeneity, potential publication bias, and the limitations of subgroup analyses, the available evidence suggests that inadequate blinding procedures could lead to exaggerated intervention effects in dry needling trials. 
1 Effectiveness and adequacy of blinding in the moderation of pain outcomes: systematic

2 review and meta-analyses of dry needling trials

3

4 Felicity A. Braithwaite ${ }^{1,2}$; Dr Julie L. Walters ${ }^{1}$; Lok Sze Katrina Li ${ }^{1}$; Professor G. Lorimer

5 Moseley $^{1,2}$; Associate Professor Marie T. Williams ${ }^{1,3}$; Dr Maureen P. McEvoy ${ }^{1}$

6

$7 \quad{ }^{1}$ School of Health Sciences, University of South Australia, Adelaide, Australia; ${ }^{2}$ Body in Mind 8 research group, University of South Australia, Adelaide, Australia; ${ }^{3}$ Alliance for Research in

9 Exercise, Nutrition and Activity (ARENA), University of South Australia, Adelaide, Australia. 10

11 Corresponding author:

12 Felicity A. Braithwaite

13 Email: felicity.braithwaite@gmail.com

Previous presentation of the research: The findings of this systematic review were presented 16 at the Australian Physiotherapy Association Conference (19-21 October, 2017). 


\section{Abstract}

Background: Blinding is critical to clinical trials because it allows for separation of specific intervention effects from bias, by equalising all factors between groups except for the proposed mechanism of action. Absent or inadequate blinding in clinical trials has consistently been shown in large meta-analyses to result in overestimation of intervention effects. Blinding in dry needling trials, particularly blinding of participants and therapists, is a practical challenge; therefore, specific effects of dry needling have yet to be determined. Despite this, dry needling is widely used by health practitioners internationally for the treatment of pain. This review presents the first empirical account of the influence of blinding on intervention effect estimates in dry needling trials. The aim of this systematic review was to determine whether participant beliefs about group allocation relative to actual allocation (blinding effectiveness), and/or adequacy of blinding procedures, moderated pain outcomes in dry needling trials.

Methods: Twelve databases (MEDLINE, EMBASE, AMED, Scopus, CINAHL, PEDro, The Cochrane Library, Trove, ProQuest, three trial registries) were searched from inception to February 2016. Trials that compared active dry needling with a sham that simulated dry needling were included. Two independent reviewers performed screening, data extraction, and critical appraisal. Available blinding effectiveness data were converted to a blinding index, a quantitative measurement of blinding, and meta-regression was used to investigate the influence of the blinding index on pain. Adequacy of blinding procedures was based on critical appraisal, and subgroup meta-analyses were used to investigate the influence of blinding adequacy on pain. Meta-analytical techniques used inverse-variance random-effects models.

Results: The search identified 4894 individual publications with 24 eligible for inclusion in the quantitative syntheses. In 19 trials, risk of methodological bias was high or unclear. Five trials were adequately blinded, and blinding was assessed and sufficiently reported to compute the blinding index in 10 trials. There was no evidence of a moderating effect of blinding index on pain. For short-term and long-term pain assessments, pooled effects for inadequately blinded trials were statistically significant in favour of active dry needling, whereas there was no evidence of a difference between active and sham groups for adequately blinded trials.

Discussion: The small number and size of included trials meant there was insufficient evidence to conclusively determine if a moderating effect of blinding effectiveness or adequacy existed. However, with the caveats of small sample size, generally unclear risk of bias, statistical 
48 heterogeneity, potential publication bias, and the limitations of subgroup analyses, the available

49 evidence suggests that inadequate blinding procedures could lead to exaggerated intervention 50 effects in dry needling trials.

51 PROSPERO registration number: 42016029340.

52

53

54 


\section{Background}

Blinding is widely considered critical to the internal validity of clinical trials because it allows separation of specific intervention effects from effects due to bias. This separation is possible because blinding equalises all factors between groups except for the proposed mechanism of action of the intervention under investigation (Hróbjartsson et al. 2014).

Blinding adequacy relates to procedures in the design of a trial to blind relevant parties (i.e. trial staff, therapists, recipients, outcome assessors, data analysts). In the absence of adequate procedures, the inclination of these parties to favour a particular result can lead to distorted findings that most commonly manifest as exaggerated intervention effects (Hróbjartsson et al. 2014; Hróbjartsson et al. 2012; Hróbjartsson et al. 2013; Jüni et al. 2001; Moher et al. 2010; Nüesch et al. 2009; Savović et al. 2012; Schulz et al. 1995; Wood et al. 2008). For example, a review of trials involving head-to-head comparisons of blinded versus non-blinded participants demonstrated pronounced bias in non-blinded groups for complementary/alterative interventions ( $\mathrm{N}=12$ trials, 11 of which were acupuncture trials) (Hróbjartsson et al. 2014). Self-reported outcomes such as pain, which is often used to evaluate physical interventions, are particularly susceptible to the effects of inadequate blinding procedures (Hróbjartsson et al. 2014; Hróbjartsson et al. 2013; Moher et al. 2010; Savović et al. 2012; Wood et al. 2008). The complex nature of physical interventions means that blinding of relevant parties, particularly participants and therapists, is often extremely difficult (Boutron et al. 2004). As a result, blinding procedures for these types of interventions have been generally inadequate or omitted completely (ArmijoOlivo et al. 2017; Boutron et al. 2007; Boutron et al. 2004; Machado et al. 2008; Moseley et al. 2011).

Inclusion of adequate blinding procedures is recognised as crucial to robust trial design (Moher et al. 2010), but evaluation of the actual effectiveness of blinding procedures and its influence on clinical trial outcomes has been poorly addressed (Bang et al. 2010; Fergusson et al. 2004; Hróbjartsson et al. 2007). Needling therapies [acupuncture and dry needling (DN)] provide a unique intervention on which to focus evaluation of blinding effectiveness, because unlike trials of many other physical interventions (Armijo-Olivo et al. 2017; Hróbjartsson et al. 2007; Machado et al. 2008; Villamar et al. 2013), blinding assessments are becoming common practice 
86

87

88

89

90

91

92

in needling therapy trials (Moroz et al. 2013). In addition, needling therapies are growing globally in popularity to manage pain (Cagnie et al. 2013; Carlesso et al. 2014; Dommerholt 2011; Legge 2014) and encompass a range of factors known to predict large non-specific responses; needling therapies are ritualistic, invasive, involve a medical device, are highly credible to patients, and are often held in high regard by the person delivering them (Benedetti 2013; Finniss et al. 2010; Kaptchuk 2002; Kaptchuk et al. 2008; Kaptchuk \& Miller 2015; Kaptchuk et al. 2006). Exaggeration of intervention effects in acupuncture is associated with expectation of intervention outcomes (Colagiuri \& Smith 2011; Linde et al. 2007), and in acupuncture trials, beliefs about group allocation have been shown to bear a stronger relationship to pain than actual allocation (Bausell et al. 2005; Vase et al. 2013; White et al. 2012). These findings suggest that failed blinding could be a significant confounder of trial outcomes, and confirms that well-blinded trials will be required to determine the mechanisms of needling therapies. However, a recent systematic review of acupuncture and dry needling trials $(\mathrm{N}=54$ trials) reported that only $61 \%$ of trials might have had effective participant blinding based on empirical data (i.e. where participant beliefs about the intervention to which they were allocated were approximately balanced between active and sham groups) (Moroz et al. 2013). Ineffective participant blinding, coupled with potentially inadequate or omitted blinding procedures for other relevant parties (particularly therapists), calls into question any specific intervention effect of needling therapy reported to date.

This systematic review presents the first empirical account of the influence of blinding on intervention effect estimates in dry needling trials. Dry needling differs from acupuncture because while acupuncture needles are used, they are inserted into clinically identified locations in muscles (such as tender areas, palpable nodules or bands) rather than the largely predetermined insertion sites based on traditional Chinese medicine used in acupuncture. As such, dry needling aims at local effects whereas acupuncture aims at systemic effects. The aim of this review was to determine the influence of blinding effectiveness and blinding adequacy on pain in sham-controlled dry needling trials. Blinding effectiveness was determined by participant beliefs about group allocation relative to actual allocation, and blinding adequacy was determined by critical appraisal. This review posed two questions: (1) 'Does blinding effectiveness moderate 
116 intervention effect on pain?' and (2) 'Does blinding adequacy moderate intervention effect on 117 pain?' 
Methods

The methods complied with the Preferred Reporting Items for Systematic Reviews and MetaAnalyses (PRISMA) checklist (Moher et al. 2009). The protocol was prospectively registered with the International Prospective Register of Systematic Reviews (PROSPERO) (registration number: 42016029340; URL:

www.crd.york.ac.uk/prospero/display_record.asp?ID=CRD42016029340).

\section{Disclosure of deviations from prospectively registered protocol}

Following original registration on March 2, 2016, two changes were made to the protocol of this review: (1) the data extraction template was pilot tested using an iterative process rather than a sample of 10 included trials, and percentage agreement was used to determine agreement, rather than an intra-class correlation coefficient (ICC); and (2) the time-point that was used to investigate the influence of blinding effectiveness on pain outcomes was the time-point at which blinding was assessed (instead of the pre-defined time-points of immediate, short-term, and longterm pain assessments), because the authors agreed that this time-point would most accurately reflect intervention beliefs (i.e. blinding effectiveness) as beliefs can change over time (Bang et al. 2010; Rees et al. 2005). The second change was updated in PROSPERO prior to data analyses (revision posted on February 5, 2017). This review presents only review questions 1 and 2 of the protocol; review questions 3 and 4 will be reported elsewhere.

\section{Information sources and search strategy}

One reviewer (FAB) executed the search strategy. Databases (MEDLINE, EMBASE, AMED, Scopus, CINAHL, PEDro, The Cochrane Library) were searched from inception to February 2016. The general search terms were (needl* OR acupuncture OR intramuscular stimulation) AND (sham OR placebo*), and Medical Subject Headings (MeSH) were used where possible. The full electronic search strategy for MEDLINE is presented in Table 1. Searches were modified to suit the functionality of each database. Thesis databases (Trove, ProQuest) and clinical trial registries [Australian New Zealand Clinical Trials Registry (ANZCTR), Clinicaltrials.gov, World Health Organization International Clinical Trials Registry Platform (WHO ICTRP)] were crosschecked with database searches to identify further potential trials. 
148 The reference lists of systematic reviews identified by the search were examined to locate

149 additional or unpublished trials. There were no limits on year, language, or publication status.

150

151

152

153

154

155

156

157

158

159

160

161

162

163

164

165

166

167

168

169

170

171

172

173

174

175

176

177

\section{Eligibility and study selection}

\section{INSERT TABLE 1 ABOUT HERE}

Trials were eligible for inclusion in this review if they (1) were prospective experimental designs (e.g. randomised, non/quasi-randomised trials, pre-post, n-of-1) of any duration, which included a 'real' dry needling intervention (referred to as 'active' dry needling in this review) and a placebo/sham dry needling intervention; (2) included human adults ( $\geq 18$ years of age) who were asymptomatic or with symptomatic health conditions; (3) involved a recognised dry needling approach with needle insertion sites based on anatomical or clinical rationales; (4) assessed and reported an outcome for pain [visual analogue scale (VAS) or numeric rating scale (NRS)]. Trials were also eligible for inclusion if they reported blinding assessment data, without reporting on pain, but the results from these trials are not presented in this review. Trials were ineligible for inclusion if the needling therapy involved pre-designated needle insertion sites (e.g. traditional acupuncture points) or involved injection of a substance (wet needling).

Records identified from the search strategy were exported to Endnote, duplicates were removed, and the remaining records were imported into the online screening tool 'Covidence systematic review software' (2018). Titles and abstracts were screened against the eligibility criteria by three independent reviewers in teams of two (FAB and MPM or JLW), and trials potentially meeting the criteria were progressed to full text review. The same three reviewers independently screened the full-text articles in teams of two. Discrepancies were resolved through discussion, with an independent third reviewer (MPM, JLW, or LSKL) consulted where necessary. Where full-text was unavailable, authors were contacted to clarify eligibility and/or to provide full-texts. Non-English publications were translated using Google Translate; the extracted data were then checked with fluent speakers of each language.

\section{Data extraction and Risk of Bias (RoB) assessment}


178 A prospectively designed data extraction template was developed based on the Standards for 179 Reporting Interventions in Controlled Trials of Acupuncture (STRICTA) (MacPherson et al.

192 2010) and the Cochrane Handbook 'Checklist of items to consider in data collection or data extraction' (Higgins \& Green 2011). The domains of data extraction were: source details, trial demographics, trial design, participant details, therapist details, intervention details, outcomes (pain and blinding assessment), blinding strategies, sample size and dropouts, results (pain and blinding assessment), and key conclusions of the authors.

The provisional data extraction template was pilot tested for inter-rater agreement by two reviewers (FAB and JLW) using an iterative process (two randomly selected included trials in each iteration). Once the pre-specified level of inter-rater agreement was established ( $\geq 75 \%$ agreement of items within an individual trial), two independent reviewers performed the remaining data extraction (FAB and LSKL, JLW, or MPM), with a third reviewer consulted to resolve disagreements as required.

Only data from the first phase of crossover trials were extracted due to the risk of carry-over intervention effects. Where necessary (i.e. where no text or table data were provided), graphical data were extracted using a ruler; if there were differences in these values between the two extracting reviewers, the average value was calculated. Pain intensity data were converted to a 100-point continuous scale where required (e.g. if collected using a $10 \mathrm{~cm}$ VAS or an NRS).

Risk of Bias (RoB) of individual trials was assessed using the Cochrane RoB assessment tool for randomised trials (because all included studies were randomised trials) (Higgins et al. 2011). Three key domains (allocation concealment, performance bias, detection bias) were determined $a$ priori based on relevance to the review questions. The key domains were informed by empirical evidence for the likelihood and magnitude of these biases influencing trial outcomes (Higgins et al. 2011; Hróbjartsson et al. 2014; Hróbjartsson et al. 2013; Savović et al. 2012; Wood et al. 2008). The overall RoB for individual trials was determined using the three key domains (low $=$ low RoB for all key domains, unclear $=$ low or unclear RoB for all key domains, high $=$ high RoB for one or more key domains) (Higgins et al. 2011). Two independent reviewers appraised 
208

209

210

211

212

213

214

215

216

217

218

219

220

221

222

223

224

225

226

227

228

229

230

231

232

233

234

235

236

237

each trial (FAB and MPM, JLW, or LSKL), with a third reviewer consulted to resolve disagreements as required.

Publication bias for each meta-analysis was assessed by visual inspection of asymmetry of funnel plots, which were contour-enhanced to allow consideration of the potential influence of the statistical significance of trial outcomes on publication bias (Peters et al. 2008). A statistical test for asymmetry was also computed for funnel plots containing $\geq 10$ trials using the method specified in Egger et al. (1997) at a significance level of $\mathrm{p}<0.10$ (Higgins \& Green 2011; Sterne et al. 2011).

\section{Data syntheses}

For both review questions, meta-analyses used generic inverse variance and random-effects models. Restricted Maximum Likelihood (REML) was used to estimate between-trial variance. Stata statistical software (version 15.1) (StataCorp. 2017) was used to compute inferential statistics and create plots. The $\mathrm{x}^{2}$ test and $I^{2}$ statistic were used to assess statistical heterogeneity; $\mathrm{p}<0.10$ was interpreted as statistically significant heterogeneity and $I^{2}>50 \%$ was interpreted as substantial heterogeneity (Higgins \& Green 2011). Intervention effects were interpreted as statistically significant when $\mathrm{p}<0.05$, and between-group effect sizes [Standardised Mean Difference (SMD)] were considered large if $>0.80$, moderate if between 0.20 and 0.80 , and small if $<0.20$ as defined by Cohen (1988).

A blinding index (BI) (Bang et al. 2004) was used to quantify the effectiveness of blinding (participant belief about group allocation relative to actual group allocation), where blinding assessments were sufficiently reported. The BI estimates the degree of unblinding (i.e. correct identification of group allocation) beyond random chance (Bang et al. 2004). To assist with interpretation of blinding effectiveness, groups within included trials were classified based on the BI cut-offs proposed by Moroz et al. (2013) (Table 2). Trials were then categorised based on paired classifications for the active and sham groups, termed a 'blinding scenario' (e.g. 'Correct/Incorrect', which means that the active group was classified as 'Correct' and the sham group was classified as 'Incorrect') (Bang et al. 2010). Using this classification method, a total of 
238 nine blinding scenarios were possible (Bang et al. 2010). The ' $\mathrm{R}$ ' software package (version

239 3.4.3) (R Core Team 2017) was used to compute BIs and their 95\% Confidence Intervals (CIs).

240

241

242

243

244

245

246

247

248

249

250

251

252

253

254

255

256

257

258

259

260

261

262

263

264

265

266

267

\section{INSERT TABLE 2 ABOUT HERE}

Review question 1: Does blinding effectiveness moderate intervention effect on pain?

It was hypothesised that if the proportion of participants who believed they had the active or sham intervention differed between active and sham groups (i.e. unbalanced intervention beliefs), this would have a moderating effect on between-group pain outcomes (i.e. increase or decrease between-group differences). To interrogate the hypothesis, a summary value for blinding effectiveness for each trial was calculated by adding the BI scores from each group (i.e. BI active group + BI sham group) [adapted from Freed et al. (2014)], and a meta-regression of the influence of the summary BI (blinding effectiveness) on between-group effect size (pain) was computed for the time-point closest to which blinding was assessed (as this is likely to most accurately reflect intervention beliefs at that moment).

Review question 2: Does blinding adequacy moderate intervention effect on pain?

The Cochrane RoB tool (Higgins et al. 2011) was also used to assess blinding adequacy of trials. Adequacy was based on the four RoB domains that relate to blinding (allocation concealment, participant blinding, therapist blinding, and outcome assessor blinding) (Higgins et al. 2011) [adapted from Feys et al. (2014)]. Trials were conservatively categorised as either 'adequately blinded' or 'inadequately blinded' based on the following rules:

- Adequately blinded: low RoB across all four domains, or low RoB in the three domains excluding 'therapist blinding' if no trials attempted therapist blinding.

- Inadequately blinded: high or unclear RoB in at least one domain.

Meta-analyses were used to assess differences in between-group effect sizes based on adequacy of blinding. It was hypothesised that inadequate blinding would favour active dry needling. Separate meta-analyses were completed for three time-periods: immediately after the first/only intervention ( $<24$ hours); short-term ( 24 hours to one month from baseline, using closest 
268

269

270

271

272

273

274

275

276

277

278

279

280

281

282

283

284

285

286

287

288

289

290

291

292

293

294

295

296

297

assessment to one week); long-term (one to six months from baseline, using closest assessment to three months).

\section{Results}

Outcome of search strategy

The outcome of the search strategy is presented in Fig. 1. The search identified 11835 records. Four additional publications were identified by searching personal records (Itoh et al. 2004) and through hand searching reference lists of 199 systematic reviews (Itoh \& Katsumi 2005; Itoh et al. 2006b; Katsumi et al. 2004). Following removal of duplicates, 4894 potentially relevant publications were screened. Title and abstract screening excluded 4280 publications. Of the remaining 614 publications, 588 were excluded following full-text review, leaving 26 publications (Fig. 1). The exclusion of two research questions from the current review resulted in the exclusion of three trials (within one publication) from this review because they did not report a pain outcome (Braithwaite 2014) (this publication is included in Fig. 1 because the two omitted review questions that did include results from this publication are reported elsewhere). The 25 relevant publications included one trial that presented results over two publications (Tough et al. 2010; Tough et al. 2009), and two single publications with two eligible sham groups (Itoh \& Katsumi 2005; Itoh et al. 2007); therefore, 25 publications (with 26 group comparisons from 24 trials) are presented in the current review. Of these 25 publications, 24 publications (with 25 group comparisons from 23 trials) provided sufficient data for inclusion in the current metaanalyses. For the meta-analyses, in the two trials with two eligible sham groups (Itoh \& Katsumi 2005; Itoh et al. 2007) the active group data were used twice.

\section{INSERT FIG. 1 ABOUT HERE}

Five non-English publications were included in the current three Japanese publications (Itoh \& Katsumi 2005; Itoh et al. 2006b; Katsumi et al. 2004) and two Spanish publications (Espejo Antúnez et al. 2014; García-Gallego et al. 2011). 
298

299

300

301

302

303

312

Of 22 authors who were contacted to clarify eligibility and/or to provide full-texts, 12 replied confirming ineligibility and 10 did not reply. For eight further records, author contact details could not be found. Nine authors of included trials were contacted to clarify trial details or request data; one author replied stating they no longer had access to the data, and the remaining eight authors did not reply.

\section{Risk of Bias (RoB) assessment}

A summary of results for the RoB assessment is presented in Table 3. Overall RoB was high in one trial, unclear in 18 trials, and low in five trials (Table 3). The areas with least RoB were participant blinding and reporting bias (low RoB in all included trials). The areas with greatest potential for bias were blinding of therapists and research personnel (high or unclear RoB in all included trials), allocation concealment, and attrition bias (Table 3).

\section{INSERT TABLE 3 ABOUT HERE}

\section{Assessment of publication bias}

Visual inspection of asymmetry of contour-enhanced funnel plots suggested that publication bias may be present (Fig. 2) (Peters et al. 2008). A statistical test for asymmetry was computed for funnel plots containing $\geq 10$ group comparisons (Fig. 2A, 2C, and 2D) and a statistically significant result was found for all three plots $(\mathrm{p}<0.001, \mathrm{p}=0.083$, and $\mathrm{p}=0.061$, respectively), which further supports the presence of publication bias (Egger et al. 1997).

\section{INSERT FIG. 2 ABOUT HERE}

\section{Description of included trials}

Table 4 presents a summary of trial characteristics and results of the 24 trials involving 26 group comparisons. Non-penetrating (NP) shams were used in 16 group comparisons, penetrating (P) shams were used in nine group comparisons, and one group comparison used anaesthesia (general or spinal) to blind participants (Mayoral et al. 2013) (Table 4). The 16 NP devices were guide-tubes alone ( $\mathrm{N}=3$ group comparisons), custom-made blunted/retracting needles $(\mathrm{N}=12$ 
group comparisons), and one commercial device [the Park sham (Park et al. 1999)]. Of the nine group comparisons that used penetrating shams, six inserted needles subcutaneously only [i.e. superficial dry needling above trigger points (TrP SDN) or away from trigger points (Non-TrP $\mathrm{SDN}$ )], and three inserted needles into muscle but away from trigger points (Non-TrP DN) (Table 4).

\section{INSERT TABLE 4 ABOUT HERE}

Fourteen trials (16 group comparisons) assessed blinding effectiveness ( $\mathrm{N}=13$ trials) or intervention credibility ( $\mathrm{N}=1$ trial). To assess blinding effectiveness, participants were asked whether they thought a needle had been inserted ( $\mathrm{N}=9$ trials), if they felt a 'needling sensation' $(\mathrm{N}=1$ trial), or which group they thought they were in $(\mathrm{N}=1$ trial). The remaining two trials did not report how blinding was assessed (Huguenin et al. 2005; Sterling et al. 2015). To assess intervention credibility, participants completed the Credibility/Expectancy Questionnaire (CEQ) (Devilly \& Borkovec 2000) ( $\mathrm{N}=1$ trial). Of the 13 trials that assessed blinding effectiveness, 10 trials (12 group comparisons) presented blinding data in a way that the BI could be calculated for active and sham groups (Table 4). To evaluate blinding effectiveness, nine trials used inferential statistics to determine if there was a difference in proportions of guesses, and four trials described, but did not statistically analyse, the blinding data (Table 4). For pain outcome assessments, 22 trials used a VAS $(\mathrm{N}=11$ trials used a $100 \mathrm{~mm}$ scale and $\mathrm{N}=11$ trials used a $10 \mathrm{~cm}$ scale) and two trials used an NRS (NRS 0-10).

\section{Data syntheses}

Review question 1: Does blinding effectiveness moderate intervention effect on pain? Figure 3 presents a bubble plot (meta-regression) of the influence of the summary BI on effect size (pain). There was no evidence of a moderating effect of the summary BI on effect size [meta-regression coefficient -1.87 (95\% CI -5.63 to 1.88); $\mathrm{p}=0.292 ; \mathrm{N}=12$ group comparisons; $\mathrm{n}=248$ ] (Fig. 3). There was evidence of statistically significant and substantial statistical heterogeneity $\left(I^{2}=79.0 \% ; \mathrm{p}<0.001\right)$ (Higgins \& Green 2011). 
360

361

362

363

364

365

366

367

368

369

370

371

372

373

374

375

376

377

387

388

389

390

Review question 2: Does blinding adequacy moderate intervention effect on pain?

Five of the 24 trials were adequately blinded (Table 3). All trials demonstrated adequate

participant blinding and no trials attempted to blind therapists, so by default blinding adequacy was determined based on the remaining two domains (allocation concealment and blinding of outcome assessors).

Immediate intervention effect ( $<24$ hours after the first/only intervention)

There were seven group comparisons where immediate pain outcomes were collected (Fig. 4).

One group comparison ( $\mathrm{n}=31)$ met the requirements for adequate blinding (Inoue et al. 2006), and intervention effects were statistically significant in favour of active dry needling [SMD -0.76 ( $95 \%$ CI -1.49 to -0.03$)$ ]. For inadequately blinded group comparisons $(\mathrm{N}=6 ; \mathrm{n}=206)$, there was no evidence of a difference in intervention effects between active and sham groups [pooled SMD $-0.47(95 \% \mathrm{CI}-0.95$ to 0.02$)]$. There was evidence of significant and substantial heterogeneity in the pooled group comparisons (Higgins \& Green 2011) (Fig. 4).

\section{INSERT FIG. 4 ABOUT HERE}

Short-term intervention effect (24 hours to one month, closest assessment to one week) There were 20 group comparisons where short-term pain outcomes were collected (Fig. 5). For adequately blinded group comparisons $(\mathrm{N}=3 ; \mathrm{n}=122)$ there was no evidence of a difference in intervention effects between active and sham groups [pooled SMD -0.40 (95\% CI -0.96 to 0.15)], whereas inadequately blinded group comparisons $(\mathrm{N}=17 ; \mathrm{n}=504)$ had statistically significant intervention effects that favoured active dry needling [pooled SMD -0.71 (95\% CI -1.05 to $0.38)$ ]. There was evidence of statistically significant and substantial heterogeneity of pooled group comparisons for the inadequately blinded subgroup, whereas the adequately blinded subgroup had moderate heterogeneity that was not significant (Higgins \& Green 2011) (Fig. 5). 
391 There were 16 group comparisons where long-term pain outcomes were collected (Fig. 6). For

402

403

404

405

406

407

408

409

410

411

412

413

414

415

416

417

418

419

420

421 adequately blinded group comparisons $(\mathrm{N}=4 ; \mathrm{n}=202)$ there was no evidence of a difference in intervention effects between active and sham groups [pooled SMD -0.30 (95\% CI -0.62 to 0.02)], whereas inadequately blinded group comparisons $(\mathrm{N}=12 ; \mathrm{n}=284)$ had statistically significant intervention effects that favoured active dry needling [pooled SMD -1.14 (95\% CI -1.64 to $0.65)]$. There was evidence of statistically significant and substantial heterogeneity of pooled group comparisons for the inadequately blinded subgroup, whereas the adequately blinded subgroup had low heterogeneity that was not significant (Higgins \& Green 2011) (Fig. 6).

\section{INSERT FIG. 6 ABOUT HERE}

\section{Discussion}

\section{Key findings}

This review aimed to determine whether blinding effectiveness and/or blinding adequacy moderated pain outcomes in dry needling trials. Of the 23 trials included in the meta-analyses, only $10(43.5 \%)$ reported data that were sufficient to calculate the BI, and only five $(21.7 \%)$ reported adequate blinding procedures. The small number and size of included trials meant that there was insufficient evidence to determine if a moderating effect of blinding effectiveness or adequacy existed (Button et al. 2013; Higgins \& Green 2011).

\section{Review question 1: Does blinding effectiveness moderate intervention effect on pain?}

Blinding effectiveness was determined based on participant beliefs about whether they received active or sham dry needling. Table 5 presents the hypothesised moderation effect of the nine possible blinding scenarios on pain outcomes [adapted from Bang et al. (2010)], and the number of group comparisons in this review that fell into those scenarios. In this hypothesis, within each group (active or sham), intervention benefits would increase as more participants believe they received active dry needling ( $\boldsymbol{\uparrow}$; Table 5). Theoretically, effective blinding would exist in Scenarios 4,5 , or 6 , where intervention beliefs were approximately balanced between groups (shaded in Table 5). In contrast, the imbalance in active and sham groups in Scenarios 1-3 would favour the sham group and in 7-9 would favour the active group. 
It was hypothesised that unbalanced beliefs between active and sham groups would moderate between-group differences in pain. No evidence of a moderating effect of the summary BI on pain was found, but the analysis may have been underpowered to detect it, as too it may have been underpowered to confidently conclude against it. Only 12 group comparisons were included in the analysis, marginally more than the minimum recommended number $(\mathrm{N}=10)$ for a metaregression (Higgins \& Green 2011). The current findings are in contrast to previous studies where significant associations between intervention outcomes and beliefs about allocation have been demonstrated (Baethge et al. 2013; Dar et al. 2005; McRae et al. 2004), including pain outcomes in acupuncture trials (Bausell et al. 2005; Vase et al. 2013; White et al. 2012). Intervention effects favoured active dry needling irrespective of whether intervention beliefs were balanced between groups; this finding is consistent with Moroz et al. (2013) who found that outcomes.

Inconsistent techniques and incomplete reporting of blinding assessments make it difficult to draw robust conclusions. Overall, 14 trials (58\%) in this review reported some form of blinding effectiveness or intervention credibility data, which is markedly greater than in previous samples [e.g. between $2-8 \%$ of random samples of clinical trials reported assessments of blinding (Fergusson et al. 2004; Hróbjartsson et al. 2007)]. However, of these 14 trials, only 10 reported data that were sufficient to calculate the BI. Where reported blinding data were insufficient to calculate the BI, authors were contacted to request the raw data but authors either did not respond or no longer had access to the data. Given the strong motivation to report success, there 
452 is a possibility of underreporting when blinding assessments indicate ineffective blinding (i.e.

453

454

455

456

457

458

459

460

461

462

463

464

465

466

467

468

469

470

471

472

473

474

475

476

477

478

479

480

481

482 reporting bias) (Hróbjartsson et al. 2007).

The lack of data to confirm the influence of blinding effectiveness on trial outcomes means that currently blinding 'success' is largely subjective (Bang et al. 2010). This is evidenced by the universal author conclusion of blinding 'success' (where reported), despite varied patterns in the blinding data (Table 4).

Review question 2: Does blinding adequacy moderate intervention effect on pain?

It was hypothesised that inadequate blinding procedures would exaggerate intervention effects.

Threats to the internal validity of included trials, coupled with the limitations of meta-analytical techniques precluded definitive conclusions. For immediate assessments, there was no evidence of a difference in intervention effects between adequately and inadequately blinded group comparisons (Fig. 4), but drawing inferences from this finding is difficult due to the small sample of group comparisons ( $\mathrm{N}=7$; with only $\mathrm{N}=1$ adequately blinded). However, with the caveats of small samples, generally unclear RoB, and the limitations of subgroup analyses, the available evidence suggests that inadequate blinding procedures could lead to exaggerated intervention effects in dry needling trials in the short-term and long-term.

In the short-term and long-term, there were statistically significant intervention effects in favour of active dry needling for inadequately blinded group comparisons, whereas adequately blinded group comparisons showed no difference between groups (Fig. 5 and 6). Differences in pooled pain outcomes between inadequately and adequately blinded group comparisons were moderate to large (short-term difference in $\mathrm{SMD}=0.31$; long-term difference in $\mathrm{SMD}=0.84$ ), and in the long-term there was no overlap of pooled $95 \%$ CIs (i.e. significance guaranteed at $\mathrm{p}<0.05$ ). In addition, in both the short-term and long-term, the adequately blinded group comparisons had more statistically homogenous results, and in the long-term the 95\% CI for adequately blinded comparisons was also more precise despite having fewer group comparisons. These findings together suggest that inadequate blinding might be associated with greater heterogeneity and lower precision in group comparisons. 
483 The current findings are consistent with the findings of previous meta-analyses investigating

484

485

486

487

488

489

490

491

492

493

494

495

496

497

498

499

500

501

502

503

504

505

506

507

508

509

510

511

512

513

moderating effects of inadequate blinding procedures (Hróbjartsson et al. 2014; Savović et al. 2012). More specifically, exaggeration of intervention effects has been found in trials with inadequate allocation concealment and/or outcome assessor blinding (Hróbjartsson et al. 2012; Hróbjartsson et al. 2013; Jüni et al. 2001; Nüesch et al. 2009; Schulz et al. 1995; Wood et al. 2008), and these two domains were the only determinates of blinding adequacy in the current review because all included trials demonstrated adequate participant blinding and no trials attempted to blind therapists.

Lack of adequate blinding procedures means that at present, specific effects of dry needling cannot be distinguished from effects due to bias. Blinding of therapists and research personnel was either not attempted or poorly reported by all included trials (Table 3). There are clearly substantial practical challenges with therapist blinding, however, potential effects of non-blinded therapists (Cook et al. 2013; Gracely et al. 1985; Moher et al. 2010; Savović et al. 2012; Vase et al. 2015) warrants research in this direction. Acupuncture studies have attempted therapist blinding using custom-made sham needle devices (Takakura et al. 2010; Takakura \& Yajima 2007), which may have potential for application in future dry needling trials. Blinding of research personnel should be a relatively simple procedure and needs greater attention and/or clearer reporting. Participant attrition, another major source of potential bias, should be accounted for using statistical methods such as intention-to-treat analysis using multiple imputation, possibly with adjustments for informative missingness, or adjustments based on covariates. In addition, there were more dropouts in sham groups due to "no response to intervention' (where reported: $n=15$ in sham groups versus $n=4$ in active groups; Table 4 ), which could have contributed to biases favouring active dry needling.

\section{Strengths and limitations}

The strengths of this review included prospective peer review and registration of the protocol (PROSPERO), adherence to the PRISMA statement for reporting (Moher et al. 2009), and independent screening for trial eligibility, data extraction, and RoB assessments by two reviewers. The search strategy was comprehensive and trials were not limited to the English language. Despite attempts to limit the impact of publication bias on the current results by 
searching trial registrations and thesis databases, asymmetry of funnel plots suggests publication bias was present (Fig. 2). The small number of trials in one of the funnel plots $(<10$; Fig. 2B) meant that it could not be confidently interpreted (Egger et al. 1997; Higgins \& Green 2011).

The current findings should be interpreted with caution. The meta-analytical techniques used in this review are not randomised comparisons and are therefore observational in nature (Higgins \& Green 2011). The strength of inferences is therefore limited by potential confounding by uncontrolled covariates, and subgroups may have differed in capacity to detect effects (Higgins \& Green 2011). However, for review question 2, the a priori hypothesis, the statistical significance of the findings, and the consistency of the difference across comparisons strengthen the validity of the inferences (Oxman \& Guyatt 1992). That no studies to date have made headto-head comparisons of blinded versus non-blinded dry needling interventions precludes any further analysis, aside from indirect comparisons. The meta-analyses used random effects modelling to allow for statistical heterogeneity between trials (Higgins \& Green 2011). Homogeneity was improved for meta-analyses investigating blinding adequacy ( $I^{2}$ values $<75 \%$; Fig. 4, 5, 6), in which comparisons were grouped based on four RoB domains, for three predefined time periods, so these analyses may be more reliable (Higgins \& Green 2011).

The included trials were methodologically heterogeneous, and many were likely to have had a high risk of null findings in the presence of small to moderate effects due to insufficient power $(\mathrm{N}=20$ group comparisons with $\mathrm{n}<50$ participants, with power clearly achieved for the pain outcome in only three trials, and zero for blinding assessment outcomes) (Button et al. 2013). Trials were also clinically diverse in terms of participant health condition, pain chronicity, age, and intervention dose, which may have confounded results, in particular because the aetiology of pain may influence the specific effects of dry needling (Cagnie et al. 2013; Dommerholt 2011), as well as non-specific effects (Tracey 2010). The limited number of trials precluded investigation of potential covariates (i.e. sensitivity or multivariable meta-regression analyses) (Higgins \& Green 2011).

Contrary to best practice, active group data were used twice in several meta-analyses that included trials with two eligible sham groups (Itoh \& Katsumi 2005; Itoh et al. 2007) (Fig. 3, 5, 
545

546

547

548

549

550

551

552

553

554

6), which may have caused unit-of-analysis errors due to correlations between the nonindependent comparisons (Higgins \& Green 2011). However, due to extremely small sample sizes ( $\mathrm{n}=8$ to 10 participants in the relevant active groups) and potential differences in physiological effects of the sham interventions (i.e. penetrating versus non-penetrating) (Lund et al. 2009), it was decided that the active group data could not be split, nor could the sham groups be combined as recommended by Higgins and Green (2011).

To determine whether the current review required updating (original search completed in February 2016), a citation search was undertaken for trials included in the current systematic review (292 citations since January 2016 as at $18^{\text {th }}$ of September 2017, with reference lists of 39 potentially relevant systematic reviews also reviewed). This search revealed 47 new prospective primary studies of dry needling; of these, only one was blinded using sham dry needling and this trial did not report an assessment of blinding effectiveness (Mason et al. 2016). Addition of one trial to the current review was unlikely to significantly alter the results, therefore the review was not updated (Elkins 2018).

\section{Conclusions}

This review found insufficient data to understand moderating effects of blinding effectiveness or adequacy on pain; therefore recommendations about interpreting trial outcomes with reference to blinding are premature. However, consistent with previous reviews, the current review found a bias in favour of active dry needling when trials were inadequately blinded for short-term and long-term pain outcomes. Due to the limitations of subgroup comparative analyses and threats to the validity of the included trials (particularly insufficient power), the findings of this review should be interpreted with caution. We did not aim to determine whether or not dry needling is superior to sham, but we can confidently conclude that should researchers propose further trials in this or related areas, they should be adequately blinded and collect robust blinding data.

\section{Acknowledgements}


574 The authors would like to thank Dr. Tasha R. Stanton for her valuable assistance in the

575 preparation of this manuscript, and Dr. Beben Benyamin and Dr. Terry Boyle for their statistical 576 support with the meta-analytical techniques.

577

578

579

580

581

582

583

584

585

586

587

588

589

590

591

592

593

594

595

596

597

598

599

600

601

602

603

604

\section{References}

2018. Covidence systematic review software. Melbourne, Australia: Veritas Health Innovation, $<\mathrm{http}: / /$ www.covidence.org $>$.

Armijo-Olivo S, Fuentes J, da Costa BR, Saltaji H, Ha C, and Cummings GG. 2017. Blinding in physical therapy trials and its association with treatment effects: a meta-epidemiological study. American Journal of Physical Medicine and Rehabilitation 96:34-44.

Baethge C, Assall OP, and Baldessarini RJ. 2013. Systematic review of blinding assessment in randomized controlled trials in schizophrenia and affective disorders 2000-2010. Psychotherapy and Psychosomatics 82:152-160.

Bang H, Flaherty SP, Kolahi J, and Park JJ. 2010. Blinding assessment in clinical trials: a review of statistical methods and a proposal of blinding assessment protocol. Clinical Research and Regulatory Affairs 27:42-51.

Bang H, Ni L, and Davis CE. 2004. Assessment of blinding in clinical trials. Controlled Clinical Trials 25:143-156.

Bausell RB, Lao L, Bergman S, Lee W-L, and Berman BM. 2005. Is acupuncture analgesia an expectancy effect? Preliminary evidence based on participants' perceived assignments in two placebo-controlled trials. Evaluation and the Health Professions 28:9-26.

Benedetti F. 2013. Placebo and the new physiology of the doctor-patient relationship. Physiological Reviews 93:1207-1246.

Boutron I, Guittet L, Estellat C, Moher D, Hróbjartsson A, and Ravaud P. 2007. Reporting methods of blinding in randomized trials assessing nonpharmacological treatments. PLoS Medicine 4:370-380.

Boutron I, Tubach F, Giraudeau B, and Ravaud P. 2004. Blinding was judged more difficult to achieve and maintain in nonpharmacologic than pharmacologic trials. Journal of Clinical Epidemiology 57:543-550.

Braithwaite FA. 2014. Testing a sham dry needle for the cervical spine in healthy adults: a randomised controlled trial. Honours thesis. University of South Australia. 
605

Button KS, Ioannidis JP, Mokrysz C, Nosek BA, Flint J, Robinson ES, and Munafò MR. 2013. Power failure: why small sample size undermines the reliability of neuroscience. Nature Reviews Neuroscience 14:365-376.

Cagnie B, Dewitte V, Barbe T, Timmermans F, Delrue N, and Meeus M. 2013. Physiologic effects of dry needling. Current Pain and Headache Reports 17:1-8.

Carlesso LC, MacDermid JC, Gross AR, Walton DM, and Santaguida PL. 2014. Treatment preferences amongst physical therapists and chiropractors for the management of neck pain: results of an international survey. Chiropractic \& Manual Therapies 22:11.

Cohen J. 1988. Statistical power analysis for the behavioral sciences. Hillsdale, New Jersey: Lawrence Erlbaum Associates.

Colagiuri B, and Smith CA. 2011. A systematic review of the effect of expectancy on treatment responses to acupuncture. Evidence-Based Complementary \& Alternative Medicine 2012:12 pages.

Cook C, Learman K, Showalter C, Kabbaz V, and O'Halloran B. 2013. Early use of thrust manipulation versus non-thrust manipulation: a randomized clinical trial. Manual Therapy 18:191-198.

Cotchett MP, Munteanu SE, and Landorf KB. 2014. Effectiveness of trigger point dry needling for plantar heel pain: a randomized controlled trial. Physical Therapy 94:1083-1094.

Dar R, Stronguin F, and Etter J-F. 2005. Assigned versus perceived placebo effects in nicotine replacement therapy for smoking reduction in Swiss smokers. Journal of Consulting and Clinical Psychology 73:350-353.

Devilly GJ, and Borkovec TD. 2000. Psychometric properties of the credibility/expectancy questionnaire. Journal of Behavior Therapy and Experimental Psychiatry 31:73-86.

Diraçoğlu D, Vural M, Karan A, and Aksoy C. 2012. Effectiveness of dry needling for the treatment of temporomandibular myofascial pain: a double-blind, randomized, placebo controlled study. Journal of Back and Musculoskeletal Rehabilitation 25:285-290.

Dommerholt J. 2011. Dry needling - peripheral and central considerations. Journal of Manual \& Manipulative Therapy 19:223-227.

Egger M, Smith GD, Schneider M, and Minder C. 1997. Bias in meta-analysis detected by a simple, graphical test. BMJ 315:629-634.

Elkins M. 2018. Updating systematic reviews. Journal of Physiotherapy 64:1-3. 
Espejo Antúnez L, Gacimartín García A, Pérez Cardeñosa MR, Cardero Durán MA, de la CruzTorres B, and Albornoz-Cabello M. 2014. Efectos sobre la tensión neural adversa medida mediante test de slump tras punción seca de punto gatillo miofascial del músculo gastrocnemio [Effects on adverse neural tension by slump test after dry needling of myofascial trigger point of the gastrocnemius muscle]. Fisioterapia 36:127-134.

Fergusson D, Glass KC, Waring D, and Shapiro S. 2004. Turning a blind eye: the success of blinding reported in a random sample of randomised, placebo controlled trials. BMJ 328:5 pages.

Feys F, Bekkering GE, Singh K, and Devroey D. 2014. Do randomized clinical trials with inadequate blinding report enhanced placebo effects for intervention groups and nocebo effects for placebo groups? Systematic Reviews 3:14 pages.

Finniss DG, Kaptchuk TJ, Miller F, and Benedetti F. 2010. Biological, clinical, and ethical advances of placebo effects. Lancet 375:686-695.

Freed B, Assall OP, Panagiotakis G, Bang H, Park JJ, Moroz A, and Baethge C. 2014. Assessing blinding in trials of psychiatric disorders: A meta-analysis based on blinding index. Psychiatry Research 219:241-247.

García-Gallego R, Tormos-Claramunt L, Vilanova-Salcedo P, Morales-Rodríguez R, PérezVillalba A, and Segura-Ortí E. 2011. Efectividad de la punción seca de un punto gatillo miofascial versus manipulación de codo sobre el dolor y fuerza máxima de prensión de la mano [Effectiveness of a myofascial trigger point dry needling versus elbow manipulation on pain and maximum hand grip strength]. Fisioterapia 33:248-255.

Gracely RH, Dubner R, Deeter WR, and Wolskee PJ. 1985. Clinicians' expectations influence placebo analgesia. Lancet 325:43.

Higgins JP, Altman DG, Gøtzsche PC, Jüni P, Moher D, Oxman AD, Savović J, Schulz KF, Weeks L, and Sterne JA. 2011. The Cochrane Collaboration's tool for assessing risk of bias in randomised trials. $B M J$ 343:9 pages.

Higgins JP, and Green S. 2011. Cochrane handbook for systematic reviews of interventions. In: Higgins JP, Altman DG, and Sterne JA, editors. Cochrane handbook for systematic reviews of interventions. Chichester: The Cochrane Collaboration. 
665

666

667

668

669

670

671

Hróbjartsson A, Emanuelsson F, Thomsen ASS, Hilden J, and Brorson S. 2014. Bias due to lack of patient blinding in clinical trials. A systematic review of trials randomizing patients to blind and nonblind sub-studies. International Journal of Epidemiology 43:1272-1283.

Hróbjartsson A, Forfang E, Haahr M, Als-Nielsen B, and Brorson S. 2007. Blinded trials taken to the test: an analysis of randomized clinical trials that report tests for the success of blinding. International Journal of Epidemiology 36:654-663.

Hróbjartsson A, Thomsen ASS, Emanuelsson F, Tendal B, Hilden J, Boutron I, Ravaud P, and Brorson S. 2012. Observer bias in randomised clinical trials with binary outcomes: systematic review of trials with both blinded and non-blinded outcome assessors. $B M J$ 344:11 pages.

Hróbjartsson A, Thomsen ASS, Emanuelsson F, Tendal B, Hilden J, Boutron I, Ravaud P, and Brorson S. 2013. Observer bias in randomized clinical trials with measurement scale outcomes: a systematic review of trials with both blinded and nonblinded assessors. Canadian Medical Association Journal 185:e201-e211.

Huguenin L, Brukner PD, McCrory P, Smith P, Wajswelner H, and Bennell K. 2005. Effect of dry needling of gluteal muscles on straight leg raise: a randomised, placebo controlled, double blind trial. British Journal of Sports Medicine 39:84-90.

Inoue M, Kitakoji H, Ishizaki N, Tawa M, Yano T, Katsumi Y, and Kawakita K. 2006. Relief of low back pain immediately after acupuncture treatment - a randomised, placebo controlled trial. Acupuncture in Medicine 24:103-108.

Itoh K, Asai S, Ohyabu H, Imai K, and Kitakoji H. 2012. Effects of trigger point acupuncture treatment on temporomandibular disorders: a preliminary randomized clinical trial. Journal of Acupuncture \& Meridian Studies 5:57-62.

Itoh K, Hirota S, Katsumi Y, Ochi H, and Kitakoji H. 2008. Trigger point acupuncture for treatment of knee osteoarthritis - a preliminary RCT for a pragmatic trial. Acupuncture in Medicine 26:17-26.

Itoh K, and Katsumi T. 2005. 高齢者の慢性腰下肢痛に対する銊治療の効果 [Effect of acupuncture on chronic lumbar pain in the elderly: comparative examination on the usefulness of trigger point acupuncture]. 全日本鍼尒学会雑誌 55:530-537. 
720

721

722

723

Itoh K, Katsumi Y, Hirota S, and Kitakoji H. 2006a. Effects of trigger point acupuncture on chronic low back pain in elderly patients - a sham-controlled randomised trial. Acupuncture in Medicine 24:5-12.

Itoh K, Katsumi Y, Hirota S, and Kitakoji H. 2007. Randomised trial of trigger point acupuncture compared with other acupuncture for treatment of chronic neck pain. Complementary Therapies in Medicine 15:172-179.

Itoh K, Katsumi Y, and Kitakoji H. 2004. Trigger point acupuncture treatment of chronic low back pain in elderly patients - a blinded RCT. Acupuncture in Medicine 22:170-177.

Itoh K, Saito S, Sahara S, Naitoh Y, Imai K, and Kitakoji H. 2014. Randomized trial of trigger point acupuncture treatment for chronic shoulder pain: a preliminary study. Journal of acupuncture and meridian studies 7:59-64.

Itoh K, Wave M, Reiyo N, Kawamoto M, Hideki O, and Hiroshi K. 2006b. 大学生の肩こり被 験者を対象にしたトリガーポイント鍼治療の試み [Trigger point for college students with shoulder stiffness trial of acupuncture treatment: questionnaire survey on shoulder stiffness and clinical trial on the effect of acupuncture]. 全日本銊尒学会雑誌 56:150157.

Jüni P, Altman DG, and Egger M. 2001. Systematic reviews in health care: assessing the quality of controlled clinical trials. BMJ 323:42-46.

Kaptchuk TJ. 2002. The placebo effect in alternative medicine: can the performance of a healing ritual have clinical significance? Annals of Internal Medicine 136:817-825.

Kaptchuk TJ, Kelley JM, Conboy LA, Davis RB, Kerr CE, Jacobson EE, Kirsch I, Schyner RN, Nam BH, and Nguyen LT. 2008. Components of placebo effect: randomised controlled trial in patients with irritable bowel syndrome. BMJ 336:999-1003.

Kaptchuk TJ, and Miller FG. 2015. Placebo effects in medicine. New England Journal of Medicine 373:8-9.

Kaptchuk TJ, Stason WB, Davis RB, Legedza AR, Schnyer RN, Kerr CE, Stone DA, Nam BH, Kirsch I, and Goldman RH. 2006. Sham device v inert pill: randomised controlled trial of two placebo treatments. BMJ 332:391-397.

Katsumi Y, Itoi M, Kojima A, Takatori R, Totani Y, Hirasawa Y, and Itoh K. 2004. 高齢者の慢 性腰痛に対する阿是穴鍼療法 (くワークショップ> 鍼尒とリハビリテーション)(第 
41 回 日本リハビリテーション学術集会) [Tender point acupuncture of chronic low back pain in aged patients]. リハビリテーション医学: 日本リハビリテーション医学 会誌 41:824-829.

Legge D. 2014. A history of dry needling. Journal of Musculoskeletal Pain 22:301-307.

Linde K, Witt CM, Streng A, Weidenhammer W, Wagenpfeil S, Brinkhaus B, Willich SN, and Melchart D. 2007. The impact of patient expectations on outcomes in four randomized controlled trials of acupuncture in patients with chronic pain. Pain 128:264-271.

Lund I, Näslund J, and Lundeberg T. 2009. Minimal acupuncture is not a valid placebo control in randomised controlled trials of acupuncture: a physiologist's perspective. Chinese Medicine 4:9 pages.

Machado L, Kamper S, Herbert R, Maher C, and McAuley J. 2008. Imperfect placebos are common in low back pain trials: a systematic review of the literature. European Spine Journal 17:889-904.

MacPherson H, Altman DG, Hammerschlag R, Youping L, Taixiang W, White A, and Moher D. 2010. Revised standards for reporting interventions in clinical trials of acupuncture (STRICTA): extending the CONSORT statement. Journal of Evidence-Based Medicine 3:140-155.

Mason JS, Crowell M, Dolbeer J, Morris J, Terry A, Koppenhaver S, and Goss DL. 2016. The effectiveness of dry needling and stretching vs. stretching alone on hamstring flexibility in patients with knee pain: a randomized controlled trial. International Journal of Sports Physical Therapy 11:672-683.

Mayoral O, Salvat I, Martin MT, Martin S, Santiago J, Cotarelo J, and Rodriguez C. 2013. Efficacy of myofascial trigger point dry needling in the prevention of pain after total knee arthroplasty: a randomized, double-blinded, placebo-controlled trial. Evidence-Based Complementary \& Alternative Medicine 2013:8 pages.

McMillan AS, Nolan A, and Kelly PJ. 1997. The efficacy of dry needling and procaine in the treatment of myofascial pain in the jaw muscles. Journal of Orofacial Pain 11:307-314.

McRae C, Cherin E, Yamazaki TG, Diem G, Vo AH, Russell D, Ellgring JH, Fahn S, Greene P, and Dillon S. 2004. Effects of perceived treatment on quality of life and medical outcomesin a double-blind placebo surgery trial. Archives of General Psychiatry 61:412420. 
755

756

757

758

759

760

761

762

763

Moher D, Hopewell S, Schulz KF, Montori V, Gøtzsche PC, Devereaux P, Elbourne D, Egger M, and Altman DG. 2010. CONSORT 2010 explanation and elaboration: updated guidelines for reporting parallel group randomised trials. BMJ 340:28 pages.

Moher D, Liberati A, Tetzlaff J, and Altman DG. 2009. Preferred reporting items for systematic reviews and meta-analyses: the PRISMA statement. Annals of Internal Medicine 151:264-269.

Moroz A, Freed B, Tiedemann L, Bang H, Howell M, and Park JJ. 2013. Blinding measured: a systematic review of randomized controlled trials of acupuncture. Evidence-Based Complementary \& Alternative Medicine 2013:12 pages.

Moseley AM, Herbert RD, Maher CG, Sherrington C, and Elkins MR. 2011. Reported quality of randomized controlled trials of physiotherapy interventions has improved over time. Journal of Clinical Epidemiology 64:594-601.

Myburgh C, Hartvigsen J, Aagaard P, and Holsgaard-Larsen A. 2012. Skeletal muscle contractility, self-reported pain and tissue sensitivity in females with neck/shoulder pain and upper Trapezius myofascial trigger points - a randomized intervention study. Chiropractic \& Manual Therapies 20:10 pages.

Nabeta T, and Kawakita K. 2002. Relief of chronic neck and shoulder pain by manual acupuncture to tender points - a sham-controlled randomized trial. Complementary Therapies in Medicine 10:217-222.

Nüesch E, Reichenbach S, Trelle S, Rutjes A, Liewald K, Sterchi R, Altman DG, and Jüni P. 2009. The importance of allocation concealment and patient blinding in osteoarthritis trials: a meta-epidemiologic study. Arthritis and Rheumatism 61:1633-1641.

Oxman AD, and Guyatt GH. 1992. A consumer's guide to subgroup analyses. Annals of Internal Medicine 116:78-84.

Park J, White A, Lee H, and Ernst E. 1999. Development of a new sham needle. Acupuncture in Medicine 17:110-112.

Pecos-Martín D, Montañez-Aguilera FJ, Gallego-Izquierdo T, Urraca-Gesto A, Gómez-Conesa A, Romero-Franco N, and Plaza-Manzano G. 2015. Effectiveness of dry needling on the lower trapezius in patients with mechanical neck pain: a randomized controlled trial. Archives of Physical Medicine and Rehabilitation 96:775-781. 
Peters JL, Sutton AJ, Jones DR, Abrams KR, and Rushton L. 2008. Contour-enhanced metaanalysis funnel plots help distinguish publication bias from other causes of asymmetry. Journal of Clinical Epidemiology 61:991-996.

R Core Team. 2017. R: A language and environment for statistical computing. Vienna, Austria: R Foundation for Statistical Computing, <http://www.R-project.org/>.

Rees JR, Wade TJ, Levy DA, Colford JM, and Hilton JF. 2005. Changes in beliefs identify unblinding in randomized controlled trials: a method to meet CONSORT guidelines. Contemporary Clinical Trials 26:25-37.

Savović J, Jones HE, Altman DG, Harris RJ, Jüni P, Pildal J, Als-Nielsen B, Balk EM, Gluud C, and Gluud LL. 2012. Influence of reported study design characteristics on intervention effect estimates from randomized, controlled trials. Annals of Internal Medicine 157:429438.

Schulz KF, Chalmers I, Hayes RJ, and Altman DG. 1995. Empirical evidence of bias: dimensions of methodological quality associated with estimates of treatment effects in controlled trials. JAMA 273:408-412.

StataCorp. 2017. Stata Statistical Software: Release 15. College Station, Texas: StataCorp LLC.

Sterling M, Vicenzino B, Souvlis T, and Connelly LB. 2015. Dry-needling and exercise for chronic whiplash associated disorders (WAD): a randomised single blind placebocontrolled trial. Pain 56:635-643.

Sterne JA, Sutton AJ, Ioannidis JP, Terrin N, Jones DR, Lau J, Carpenter J, Rücker G, Harbord RM, and Schmid CH. 2011. Recommendations for examining and interpreting funnel plot asymmetry in meta-analyses of randomised controlled trials. BMJ 343:8 pages.

Takakura N, Takayama M, Kawase A, Kaptchuk TJ, and Yajima H. 2010. Double blinding with a new placebo needle: a further validation study. Acupuncture in Medicine 28:144-148.

Takakura N, and Yajima H. 2007. A double-blind placebo needle for acupuncture research. BMC Complementary and Alternative Medicine 7:5 pages.

Tekin L, Akarsu S, Durmuş O, Çakar E, Dinçer Ü, and Kıralp MZ. 2013. The effect of dry needling in the treatment of myofascial pain syndrome: a randomized double-blinded placebo-controlled trial. Clinical Rheumatology 32:309-315.

Tough EA, White AR, Richards SH, and Campbell JL. 2010. Myofascial trigger point needling for whiplash associated pain - a feasibility study. Manual Therapy 15:529-535. 
Tough EA, White AR, Richards SH, Lord B, and Campbell JL. 2009. Developing and validating a sham acupuncture needle. Acupuncture in Medicine 27:118-122.

Tracey I. 2010. Getting the pain you expect: mechanisms of placebo, nocebo and reappraisal effects in humans. Nature Medicine 16:1277-1283.

Tsai CT, Hsieh LF, Kuan TS, Kao MJ, Chou LW, and Hong CZ. 2010. Remote effects of dry needling on the irritability of the myofascial trigger point in the upper trapezius muscle. American Journal of Physical Medicine and Rehabilitation 89:133-140.

Vase L, Baram S, Takakura N, Takayama M, Yajima H, Kawase A, Schuster L, Kaptchuk TJ, Schou S, and Jensen TS. 2015. Can acupuncture treatment be double-blinded? An evaluation of double-blind acupuncture treatment of postoperative pain. PloS One 10:e0119612.

Vase L, Baram S, Takakura N, Yajima H, Takayama M, Kaptchuk TJ, Schou S, Jensen TS, Zachariae R, and Svensson P. 2013. Specifying the nonspecific components of acupuncture analgesia. Pain 154:1659-1667.

Villamar MF, Contreras VS, Kuntz RE, and Fregni F. 2013. The reporting of blinding in physical medicine and rehabilitation randomized controlled trials: a systematic review. Journal of Rehabilitation Medicine 45:6-13.

White P, Bishop FL, Prescott P, Scott C, Little P, and Lewith G. 2012. Practice, practitioner, or placebo? A multifactorial, mixed-methods randomized controlled trial of acupuncture. Pain 153:455-462.

Wood L, Egger M, Gluud LL, Schulz KF, Jüni P, Altman DG, Gluud C, Martin RM, Wood AJ, and Sterne JA. 2008. Empirical evidence of bias in treatment effect estimates in controlled trials with different interventions and outcomes: meta-epidemiological study. BMJ 336:601-605. 
Table $\mathbf{1}$ (on next page)

MEDLINE search strategy 
1 Table 1 MEDLINE search strategy

Limits applied

1. Needl*.tw

2. *Acupuncture therapy/

3. Acupuncture.tw

4. Intramuscular stimulation.tw

5. Sham.tw

6. *Placebo effect/

7. *Placebos/

8. Placebo\$1.tw

9. \#1 OR \#2 OR \#3 OR \#4

10. \#5 OR \#6 OR \#7 OR \#8

11. \#9 AND \#10
Humans only

Keyword searches limited to title/abstract/keyword fields 


\section{Table 2 (on next page)}

Interpretation of the Blinding Index (BI) and classifications

*Cut-off scores were developed by consensus of authors of Moroz et al. (2013) and should not be interpreted as definitive classifications of blinding effectiveness. BI Blinding Index. 
1 Table 2 Interpretation of the Blinding Index (BI) and classifications

\begin{tabular}{cl|cc}
\hline BI & Interpretation & BI cut-offs* & Classification \\
\hline-1.00 & All participants mistakenly guess the alternative & $\mathrm{BI} \leq-0.20$ & Incorrect \\
& intervention (incorrect guessing) & & \\
0.00 & Random guessing (ideal blinding) & $-0.20<\mathrm{BI}<0.20$ & Random \\
+1.00 & All participants correctly guess their allocation & $\mathrm{BI} \geq 0.20$ & Correct \\
& (correct guessing) & & \\
\hline
\end{tabular}

2 *Cut-off scores were developed by consensus of authors of Moroz et al. (2013) and should not

3 be interpreted as definitive classifications of blinding effectiveness. BI Blinding Index. 


\section{Table 3(on next page)}

Risk of bias assessment [Cochrane Risk of Bias tool for randomised trials (Higgins et al. 2011)]

*Key domains (used to determine overall Risk of Bias for individual trials); "Domains used to determine blinding adequacy; PB Participant Blinding; RPB Research Personnel Blinding; TB Therapist Blinding; OAB Outcome Assessor Blinding; $\checkmark$ Low RoB; ? Unclear RoB; $\boldsymbol{x}$ High RoB. 
Tiable 3 Risk of bias assessment ( $N=24$ trials) [Cochrane Risk of Bias tool for randomised trials (Higgins et al. 2011)]

\begin{tabular}{|c|c|c|c|c|c|c|c|c|c|c|c|}
\hline \multirow[t]{2}{*}{$1^{\text {st }}$ author $\&$ year } & \multirow{2}{*}{$\begin{array}{l}\text { Random } \\
\text { allocation }\end{array}$} & \multirow{2}{*}{$\begin{array}{l}{ }^{* \# A} \text { Allocation } \\
\text { concealed }\end{array}$} & \multicolumn{4}{|c|}{ Performance bias } & \multirow{2}{*}{$\begin{array}{c}{ }^{* \# \text { Detection bias }} \\
\text { (OAB) }\end{array}$} & \multirow[t]{2}{*}{ Attrition bias } & \multirow[t]{2}{*}{ Reporting bias } & \multirow[t]{2}{*}{ OVERALL } & \multirow{2}{*}{$\begin{array}{l}\text { Adequately } \\
\text { blinded? }\end{array}$} \\
\hline & & & \#PB & RPB & " & *Overall & & & & & \\
\hline Cotchett 2014 & $\checkmark$ & $\checkmark$ & $\checkmark$ & $?$ & $*$ & $\checkmark$ & $v$ & $\checkmark$ & $\checkmark$ & $v$ & Adequate \\
\hline Dıraçoğlu 2012 & $\checkmark$ & ? & $\checkmark$ & $?$ & * & $\checkmark$ & $\checkmark$ & $\mathbf{x}$ & $\checkmark$ & $?$ & Inadequate \\
\hline $\begin{array}{l}\text { Espejo Antúnez } \\
2014\end{array}$ & $\checkmark$ & $?$ & $\checkmark$ & $?$ & $\boldsymbol{x}$ & $\checkmark$ & $\checkmark$ & $\checkmark$ & $\checkmark$ & $?$ & Inadequate \\
\hline $\begin{array}{l}\text { García-Gallego } \\
2011\end{array}$ & $\checkmark$ & $?$ & $\checkmark$ & $?$ & $\boldsymbol{*}$ & $\checkmark$ & $\checkmark$ & $\checkmark$ & $\checkmark$ & $?$ & Inadequate \\
\hline Huguenin 2005 & $\checkmark$ & $\checkmark$ & $\checkmark$ & $?$ & $\mathbf{x}$ & $\checkmark$ & $\checkmark$ & * & $\checkmark$ & $v$ & Adequate \\
\hline Inoue 2006 & $\checkmark$ & $\checkmark$ & $\checkmark$ & $?$ & $x$ & $\checkmark$ & $\checkmark$ & $\checkmark$ & $\checkmark$ & $\checkmark$ & Adequate \\
\hline Itoh 2004 & $\checkmark$ & $?$ & $\checkmark$ & $?$ & $\mathbf{x}$ & $\checkmark$ & $\checkmark$ & $\boldsymbol{x}$ & $\checkmark$ & $?$ & Inadequate \\
\hline Itoh 2005 & $\checkmark$ & $\checkmark$ & $\checkmark$ & ? & $x$ & $\checkmark$ & $\checkmark$ & $\boldsymbol{x}$ & $\checkmark$ & $\checkmark$ & Adequate \\
\hline Itoh 2006a & $\checkmark$ & $?$ & $\checkmark$ & ? & $*$ & $\checkmark$ & $\checkmark$ & $x$ & $\checkmark$ & $?$ & Inadequate \\
\hline Itoh $2006 \mathrm{~b}$ & $?$ & ? & $\checkmark$ & $?$ & $\boldsymbol{x}$ & $\checkmark$ & $?$ & * & $\checkmark$ & $?$ & Inadequate \\
\hline Itoh 2007 & $\checkmark$ & $?$ & $\checkmark$ & $?$ & 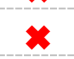 & $v$ & $\checkmark$ & $*$ & $\checkmark$ & $?$ & Inadequate \\
\hline Itoh 2008 & $\checkmark$ & $?$ & $\checkmark$ & $?$ & $\mathbf{x}$ & $\checkmark$ & $\checkmark$ & $\mathbf{x}$ & $\checkmark$ & $?$ & Inadequate \\
\hline Itoh 2012 & $\checkmark$ & $?$ & $\checkmark$ & ? & $*$ & $\checkmark$ & $\checkmark$ & $x$ & $\checkmark$ & $?$ & Inadequate \\
\hline Itoh 2014 & $\checkmark$ & ? & $\checkmark$ & ? & $\ddot{x}$ & $\checkmark$ & $\checkmark$ & $x$ & $\checkmark$ & $?$ & Inadequate \\
\hline Katsumi 2004 & $\checkmark$ & $?$ & $\checkmark$ & $?$ & $\boldsymbol{x}$ & $\checkmark$ & $?$ & $\checkmark$ & $\checkmark$ & $?$ & Inadequate \\
\hline Mayoral 2013 & $\checkmark$ & $?$ & $\checkmark$ & $?$ & $\boldsymbol{x}$ & $\checkmark$ & 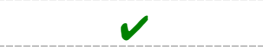 & $\boldsymbol{x}$ & $\checkmark$ & $?$ & Inadequate \\
\hline McMillan 1997 & $?$ & $?$ & $\checkmark$ & ? & $\boldsymbol{x}$ & $\checkmark$ & $\checkmark$ & $?$ & $\checkmark$ & $?$ & Inadequate \\
\hline Myburgh 2012 & $\checkmark$ & $?$ & $\checkmark$ & $?$ & $*$ & $\checkmark$ & $?$ & $*$ & $\checkmark$ & $?$ & Inadequate \\
\hline Nabeta 2002 & $\checkmark$ & ? & $\checkmark$ & $?$ & $\boldsymbol{*}$ & $\checkmark$ & $?$ & $\checkmark$ & $\checkmark$ & $?$ & Inadequate \\
\hline Pecos-Martín 2015 & $\checkmark$ & $?$ & $\checkmark$ & $?$ & 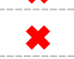 & $\checkmark$ & $\checkmark$ & $\checkmark$ & $\checkmark$ & $?$ & Inadequate \\
\hline Sterling 2015 & $\checkmark$ & $\checkmark$ & $\checkmark$ & $?$ & $\boldsymbol{x}$ & $\checkmark$ & $\checkmark$ & $\checkmark$ & $\checkmark$ & $\checkmark$ & Adequate \\
\hline Tekin 2013 & $\checkmark$ & $?$ & $\checkmark$ & ? & 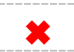 & $\checkmark$ & $\nu$ & $x$ & $\checkmark$ & $?$ & Inadequate \\
\hline Tough 2009/2010 & $\checkmark$ & ? & $\checkmark$ & $*$ & $x$ & $x$ & $?$ & $\checkmark$ & $\checkmark$ & $*$ & Inadequate \\
\hline Tsai 2010 & $\checkmark$ & $?$ & $\checkmark$ & $?$ & $*$ & $\checkmark$ & $\checkmark$ & $\checkmark$ & $\checkmark$ & $?$ & Inadequate \\
\hline
\end{tabular}

2*Key domains (used to determine overall Risk of Bias for individual trials); "Domains used to determine blinding adequacy; PB

3Participant Blinding; RPB Research Personnel Blinding; TB Therapist Blinding; OAB Outcome Assessor Blinding; $\checkmark \square$ Low RoB; ? Unclear 4RoB; $*$ High RoB.

5 


\section{Table 4 (on next page)}

Characteristics and results of included group comparisons

n number of participants (analysed for pain outcome); "Dropouts for pain outcome; $\mathbf{9 5 \%} \mathbf{~ C l}$ 95\% Confidence Interval; AG Active Group; SG Sham Group; SMD Standardised Mean Difference; -ve Negative; Ax Assessment; Ix Intervention; NP Non Penetrating; NSD No Significant Difference; CEQ Credibility/Expectancy Questionnaire; ST Short-Term (24 hours to four weeks, closest assessment to one week); LT Long-Term (one to six months, closest assessment to three months); Immed Immediately post-intervention ( $<24$ hours after first/only intervention); B time-point at which Blinding was assessed; † Data not reported as mean/SD (could not calculate SMD); NR Not Reported; DNR Did Not Respond (to intervention); AE Adverse Effects; P Penetrating; TrP SDN Superficial Dry Needling above Trigger Point; LTFU Loss To Follow Up; DK Don't Know; Non-TrP SDN Superficial Dry Needling away from Trigger Point; Non-TrP DN Dry Needling away from Trigger Point; AUC Area Under Curve; GA General Anaesthesia; SA Spinal Anaesthesia. Notes: Shading represents adequately blinded trials (based on critical appraisal criteria for Review Question 2); *Itoh et al. (2005) and *Itoh et al. (2007) each had two eligible sham groups; ^ Itoh et al. (2005) only reported the number of participants from each group who guessed they were in the active group, therefore, to calculate the BI it was conservatively assumed that the remaining participants guessed they were in the sham group (i.e. no DK responses). 
1 Table 4 Characteristics and results of included group comparisons ( $\mathrm{N}=26$ group comparisons)

\begin{tabular}{|c|c|c|c|c|c|c|c|}
\hline $\begin{array}{l}\text { 1st author \& } \\
\text { year }\end{array}$ & $n$ & $\begin{array}{l}\text { Dropouts" } \\
\text { [reasons] }\end{array}$ & Type of sham & $\begin{array}{l}\text { Blinding index }(95 \% \mathrm{Cl}) \\
\text { Blinding scenario } \\
\text { (AG/SG) }\end{array}$ & Reported blinding results & $\begin{array}{l}\text { Reported } \\
\text { blinding } \\
\text { conclusion }\end{array}$ & $\begin{array}{l}\text { Between-group SMD (pain) } \\
\text { and reported p-values } \\
\text { [-ve values in favour of AG] }\end{array}$ \\
\hline Cotchett 2014 & 84 & $\begin{array}{l}5 \\
\text { AG: } 3 \text { [1 missed Ax; } 2 \text { ceased Ix] } \\
\text { SG: } 2 \text { [1 missed Ax; } 1 \text { ceased Ix] }\end{array}$ & $\begin{array}{l}\text { NP: Custom (blunt } \\
\text { needle) }\end{array}$ & Insufficient data & $\begin{array}{l}\text { NSD between groups (CEQ) } \\
\text { ( }>0.05 \text { for all questions) }\end{array}$ & Success & $\begin{array}{l}\text { ST: }-0.05(p=0.026) \\
\text { LT: }-0.42(p=0.007)\end{array}$ \\
\hline $\begin{array}{l}\text { Huguenin } \\
2005\end{array}$ & 52 & 7 [difficulty attending] & $\begin{array}{l}\text { NP: Custom (blunt } \\
\text { needle) }\end{array}$ & Insufficient data & $\begin{array}{l}\text { AG only: } \\
\text { - Immed: Correct ( } p=0.001) \\
\text { - ST: NSD between correct and } \\
\text { incorrect guesses ( } p=0.062 \text { ) }\end{array}$ & Success & $\begin{array}{l}\text { Immed/B: † (NSD) } \\
\text { ST: † (NSD) }\end{array}$ \\
\hline Inoue 2006 & 31 & 0 & $\begin{array}{l}\text { NP: Custom (guide } \\
\text { tube only) }\end{array}$ & $\begin{array}{l}\text { AG: } 0.20(-0.30-0.70) \\
\text { SG: } 0.25(-0.22-0.72) \\
\text { Correct/Correct }\end{array}$ & $\begin{array}{l}\text { NSD between groups ( } p \text { NR) } \\
\text { AG: } 9 / 15 \text { correct } \\
\text { SG: } 10 / 16 \text { correct }\end{array}$ & Success & Immed/B: $0.76(p=0.020)$ \\
\hline $\begin{array}{l}\text { *Itoh } 2005 \\
\text { (NP) }\end{array}$ & 19 & $\begin{array}{l}3 \\
\text { AG: } 1 \\
\text { SG: } 2 \\
\text { [All groups: } 5 \text { DNR; } 2 \text { AE] }\end{array}$ & $\begin{array}{l}\text { NP: Custom (guide } \\
\text { tube only) }\end{array}$ & $\begin{array}{l}\text { ^AG: } 0.60(0.10-1.10) \\
\text { ^SG: }-0.11(-0.76-0.54) \\
\text { Correct/Random }\end{array}$ & $\begin{array}{l}\text { NSD between groups }(p=0.64) \\
\text { AG: } 8 / 10 \text { correct } \\
\text { SG: } 4 / 9 \text { correct }\end{array}$ & Success & $\begin{array}{l}\text { ST: }-0.82(p<0.05) \\
\text { B: }-2.35(p<0.01) \\
\text { LT: }-0.98 \text { (NSD) }\end{array}$ \\
\hline *Itoh 2005 (P) & 19 & $\begin{array}{l}3 \\
\text { AG: } 1 \\
\text { SG: } 2 \\
\text { [All groups: } 5 \text { DNR; } 2 \text { AE] }\end{array}$ & P: TrP SDN & $\begin{array}{l}\text { AAG: } 0.60(0.10-1.10) \\
\text { ^SG: }-0.20(-0.81-0.41) \\
\text { Correct/Incorrect }\end{array}$ & $\begin{array}{l}\text { NSD between groups ( } p=0.64 \text { ) } \\
\text { AG: } 8 / 10 \text { correct } \\
\text { SG: } 4 / 10 \text { correct }\end{array}$ & Success & $\begin{array}{l}\text { ST: }-0.77 \text { (NSD) } \\
\text { B: }-0.67(p<0.05) \\
\text { LT: }-0.13 \text { (NSD) }\end{array}$ \\
\hline Sterling 2015 & 80 & $\begin{array}{l}7 \\
\text { AG: } 3 \text { [LTFU] } \\
\text { SG: } 4 \text { [LTFU] }\end{array}$ & $\begin{array}{l}\text { NP: Commercial } \\
\text { (Park sham) }\end{array}$ & Insufficient data & $\begin{array}{l}\text { Descriptive only } \\
\text { SG: } 1 / 36 \text { correct } \\
\text { [All remaining participants } \\
\text { believed AG or DK] }\end{array}$ & Success & $\begin{array}{l}\text { LT: }-0.04 \text { (NSD) } \\
\text { B: }-0.09 \text { (NSD) }\end{array}$ \\
\hline $\begin{array}{l}\text { Diraçoğlu } \\
2012\end{array}$ & 50 & $\begin{array}{l}2 \\
\text { AG: } 1 \text { [difficulty attending] } \\
\text { SG: } 1 \text { [DNR] }\end{array}$ & P: Non-TrP SDN & Did not assess blinding & - & - & ST: $0.06(p=0.478)$ \\
\hline $\begin{array}{l}\text { Espejo } \\
\text { Antúnez } 2014\end{array}$ & 45 & 0 & $\begin{array}{l}\text { NP: Custom } \\
\text { (retracting needle) }\end{array}$ & Did not assess blinding & - & - & Immed: $-1.15(p<0.01)$ \\
\hline $\begin{array}{l}\text { García- } \\
\text { Gallego } 2011\end{array}$ & 33 & 0 & P: Non-TrP DN & Did not assess blinding & - & - & $\begin{array}{l}\text { Immed: } 0.09 \text { (NSD) } \\
\text { ST: } 0.17 \text { (NSD) }\end{array}$ \\
\hline Itoh 2004 & 18 & $\begin{array}{l}4 \\
A G: 1[A E] \\
\text { SG: } 3 \text { [DNR] }\end{array}$ & P: TrP SDN & Did not assess blinding & - & - & $\begin{array}{l}\text { ST: }-0.72 \text { (NSD) } \\
\text { LT: }-0.21 \text { (NSD) }\end{array}$ \\
\hline Itoh 2006a & 19 & $\begin{array}{l}7 \\
\text { AG: } 3 \text { [2 DNR; } 1 \text { AE] } \\
\text { SG: } 4 \text { [DNR] }\end{array}$ & $\begin{array}{l}\text { NP: Custom (blunt } \\
\text { needle) }\end{array}$ & $\begin{array}{l}\text { AG: } 0.50(0.00-1.00) \\
\text { SG: }-0.11(-0.68-0.46) \\
\text { Correct/Random }\end{array}$ & $\begin{array}{l}\text { NSD between groups }(\mathrm{p}=0.38) \\
\text { AG: } 7 / 10 \text { correct; } 1 / 10 \mathrm{DK} \\
\text { SG: } 3 / 9 \text { correct; } 2 / 9 \mathrm{DK}\end{array}$ & Success & $\begin{array}{l}\text { ST: }-1.38 \text { (NSD) } \\
\text { B: }-3.43(p<0.001) \\
\text { LT: }-1.19 \text { (NSD) }\end{array}$ \\
\hline Itoh 2006b & 18 & 5 & NP: Custom (blunt & AG: NR & Descriptive only (SG only) & NR & ST/B: $-1.11(p<0.05)$ \\
\hline
\end{tabular}




\begin{tabular}{|c|c|c|c|c|c|c|c|}
\hline & & $\begin{array}{l}\text { AG: } 2 \\
\text { SG: } 3 \\
\text { [All groups: } 4 \text { DNR; } 2 \text { drugs] }\end{array}$ & needle) & $\begin{array}{l}\text { SG: }-0.56(-1.00--0.11) \\
\text { NR/Incorrect }\end{array}$ & SG: $1 / 9$ correct; $2 / 9$ DK & & LT: -0.35 (NSD) \\
\hline $\begin{array}{l}\text { *Itoh } 2007 \\
\text { (NP) }\end{array}$ & 15 & $\begin{array}{l}5 \\
\text { AG: } 2 \text { [1 DNR; } 1 \mathrm{AE}] \\
\text { SG: } 3 \text { [2 DNR; } 1 \mathrm{AE} \text { ) }\end{array}$ & $\begin{array}{l}\text { NP: Custom (blunt } \\
\text { needle) }\end{array}$ & $\begin{array}{l}\text { AG: } 0.38(-0.11-0.86) \\
\text { SG: }-0.29(-0.94-0.37) \\
\text { Correct/Incorrect }\end{array}$ & $\begin{array}{l}\text { NSD between groups ( } p=0.89) \\
\text { AG: } 4 / 8 \text { correct; } 3 / 8 \text { DK } \\
\text { SG: } 2 / 7 \text { correct; } 1 / 7 \text { DK }\end{array}$ & Success & $\begin{array}{l}\text { ST: }-0.71 \text { (NSD) } \\
\text { B: }-1.87 \text { (NSD) } \\
\text { LT: }-2.52 \text { (NSD) }\end{array}$ \\
\hline *Itoh 2007 (P) & 16 & $\begin{array}{l}4 \\
\text { AG: } 2 \text { [1 DNR; } 1 \mathrm{AE}] \\
\text { SG: } 2 \text { [1 DNR; } 1 \mathrm{AE}]\end{array}$ & P: Non-TrP DN & $\begin{array}{l}\text { AG: } 0.38(-0.11-0.86) \\
\text { SG: }-0.38(-0.86-0.11) \\
\text { Correct/Incorrect }\end{array}$ & $\begin{array}{l}\text { NSD between groups }(p=0.89) \\
\text { AG: } 4 / 8 \text { correct; } 3 / 8 \text { DK } \\
\text { SG: } 1 / 8 \text { correct; } 3 / 8 \text { DK }\end{array}$ & Success & $\begin{array}{l}\text { ST: }-1.32 \text { (NSD) } \\
\text { B: }-2.25 \text { (NSD) } \\
\text { LT: }-3.25 \text { (NSD) }\end{array}$ \\
\hline Itoh 2008 & 15 & $\begin{array}{l}5 \\
\text { AG: } 2 \text { [1 DNR; } 1 \mathrm{AE}] \\
\text { SG: } 3 \text { [DNR] }\end{array}$ & $\begin{array}{l}\text { NP: Custom (blunt } \\
\text { needle) }\end{array}$ & $\begin{array}{l}\text { AG: } 0.75(0.29-1.21) \\
\text { SG: }-0.43(-1.10-0.24) \\
\text { Correct/Incorrect }\end{array}$ & $\begin{array}{l}\text { NSD between groups }(p=0.74) \\
\text { AG: } 7 / 8 \text { correct } \\
\text { SG: } 2 / 7 \text { correct }\end{array}$ & Success & $\begin{array}{l}\text { ST: }-1.95 \\
\text { B: }-2.67 \\
\text { LT: }-0.81 \\
\text { (AUC } p=0.025)\end{array}$ \\
\hline Itoh 2012 & 15 & $\begin{array}{l}1 \\
A G: 1[A E]\end{array}$ & $\begin{array}{l}\text { NP: Custom (blunt } \\
\text { needle) }\end{array}$ & $\begin{array}{l}\text { AG: } 1.00(1.00-1.00) \\
\text { SG: }-1.00(-1.00--1.00) \\
\text { Correct/Incorrect }\end{array}$ & $\begin{array}{l}\text { Descriptive only } \\
\text { [All participants believed they } \\
\text { were in } A G \text { ] }\end{array}$ & Success & $\begin{array}{l}\text { ST: }-0.46 \\
\text { B: }-1.83 \\
\text { LT: }-1.65 \\
\text { (AUC } p=0.003 \text { ) }\end{array}$ \\
\hline Itoh 2014 & 15 & $\begin{array}{l}1 \\
\text { SG: } 1 \text { [DNR] }\end{array}$ & $\begin{array}{l}\text { NP: Custom (blunt } \\
\text { needle) }\end{array}$ & $\begin{array}{l}\text { AG: } 0.56(0.01-1.10) \\
\text { SG: }-0.50(-1.10-0.10) \\
\text { Correct/Incorrect }\end{array}$ & $\begin{array}{l}\text { NSD between groups }(p=0.89) \\
\text { AG: } 7 / 9 \text { correct } \\
\text { SG: } 2 / 8 \text { correct }\end{array}$ & Success & $\begin{array}{l}\text { ST: }-0.96 \\
\text { B: }-1.29 \\
\text { LT: }-1.44 \\
\text { (AUC } p=0.024)\end{array}$ \\
\hline Katsumi 2004 & 9 & 0 & $\begin{array}{l}\text { NP: Custom (guide } \\
\text { tube only) }\end{array}$ & $\begin{array}{l}\text { AG: } 1.00(1.00-1.00) \\
\text { SG: }-0.60(-1.30-0.10) \\
\text { Correct/Incorrect }\end{array}$ & $\begin{array}{l}\text { Descriptive only } \\
\text { AG: } 4 / 4 \text { correct } \\
\text { SG: } 1 / 5 \text { correct }\end{array}$ & NR & $\begin{array}{l}\text { ST: }-0.64 \text { (NR) } \\
\text { B: }-4.36 \text { (NR) } \\
\text { LT: }-0.73 \text { (NR) }\end{array}$ \\
\hline Mayoral 2013 & 31 & $\begin{array}{l}9 \\
\text { AG: } 4 \text { [LTFU] } \\
\text { SG: } 5 \text { [LTFU] }\end{array}$ & No needle: GA/SA & Did not assess blinding & - & - & $\begin{array}{l}\text { ST: }-0.34(p=0.294) \\
\text { LT: }-0.23(p=0.516)\end{array}$ \\
\hline $\begin{array}{l}\text { McMillan } \\
1997\end{array}$ & 20 & NR & P: Non-TrP SDN & Did not assess blinding & - & - & $\begin{array}{l}\text { Immed: } 0.35 \text { (NSD) } \\
\text { ST: } 0.26 \text { (NSD) }\end{array}$ \\
\hline $\begin{array}{l}\text { Myburgh } \\
2012\end{array}$ & 77 & $\begin{array}{l}4 \\
\text { AG: } 4 \text { [2 non-compliant; } 1 \mathrm{AE} ; \\
1 \mathrm{NR}]\end{array}$ & P: TrP SDN & Did not assess blinding & - & - & ST: -0.37 (NSD) \\
\hline Nabeta 2002 & 34 & $\begin{array}{l}7 \\
\text { AG: } 2 \text { [difficulty attending] } \\
\text { SG: } 5 \text { [difficulty attending] }\end{array}$ & $\begin{array}{l}\text { NP: Custom (blunt } \\
\text { needle) }\end{array}$ & $\begin{array}{l}\text { AG: } 0.41(0.01-0.81) \\
\text { SG: }-0.18(-0.62-0.26) \\
\text { Correct/Random }\end{array}$ & $\begin{array}{l}\text { NSD between groups ( } p=0.74) \\
\text { AG: } 11 / 17 \text { correct; } 2 / 17 \text { DK } \\
\text { SG: } 6 / 17 \text { correct; } 2 / 17 \text { DK }\end{array}$ & Success & $\begin{array}{l}\text { Immed: }-0.12 \text { (NSD) } \\
\text { ST: }-0.31 \text { (NSD) } \\
\text { B: }-0.25 \text { (NSD) }\end{array}$ \\
\hline $\begin{array}{l}\text { Pecos-Martín } \\
2015\end{array}$ & 72 & 0 & P: Non-TrP DN & Did not assess blinding & - & - & $\begin{array}{l}\text { ST: }-1.59(p<0.001) \\
\text { LT: }-1.93(p<0.001)\end{array}$ \\
\hline Tekin 2013 & 39 & $\begin{array}{l}7 \\
\text { AG: } 1 \text { [ceased Ix] } \\
\text { SG: } 6 \text { [ceased Ix] }\end{array}$ & $\begin{array}{l}\text { NP: Custom (blunt } \\
\text { needle) }\end{array}$ & Did not assess blinding & - & - & $\begin{array}{l}\text { Immed: }-0.88(p=0.034) \\
\text { ST: }-1.62(p=0.000)\end{array}$ \\
\hline Tough & 41 & 7 & NP: Custom (blunt & AG: $0.53(0.30-0.75)$ & NSD between groups $(p>0.2)$ & Success & ST/B: 0.11 (NR) \\
\hline
\end{tabular}




\begin{tabular}{|c|c|c|c|c|c|}
\hline $2009 / 2010$ & $\begin{array}{l}\text { AG: } 3 \text { [LTFU] } \\
\text { SG: } 4 \text { [LTFU] }\end{array}$ & needle) & $\begin{array}{l}\text { SG: }-0.67(-0.93--0.40) \\
\text { Correct/Incorrect }\end{array}$ & $\begin{array}{l}\text { AG: } 10 / 19 \text { correct; } 9 / 19 \mathrm{DK} \\
\text { SG: } 1 / 18 \text { correct; } 4 / 18 \mathrm{DK}\end{array}$ & LT: $-0.61(p=0.67)$ \\
\hline Tsai 2010 & $35 \quad 0$ & P: TrP SDN & Did not assess blinding & - & Immed: -0.91 ( $p<0.05)$ \\
\hline
\end{tabular}

n number of participants (analysed for pain outcome); "Dropouts for pain outcome; $95 \%$ Cl 95\% Confidence Interval; AG Active Group; SG Sham

3 Group; SMD Standardised Mean Difference; -ve Negative; Ax Assessment; Ix Intervention; NP Non Penetrating; NSD No Significant Difference;

4 CEQ Credibility/Expectancy Questionnaire; ST Short-Term (24 hours to four weeks, closest assessment to one week); LT Long-Term (one to six months, closest assessment to three months); Immed Immediately post-intervention ( $<24$ hours after first/only intervention); B time-point at which Blinding was assessed; † Data not reported as mean/SD (could not calculate SMD); NR Not Reported; DNR Did Not Respond (to intervention); AE Adverse Effects; P Penetrating; TrP SDN Superficial Dry Needling above Trigger Point; LTFU Loss To Follow Up; DK Don't Know; Non-TrP SDN Superficial Dry Needling away from Trigger Point; Non-TrP DN Dry Needling away from Trigger Point; AUC Area Under Curve; GA General Anaesthesia; SA Spinal Anaesthesia.

Notes: Shading represents adequately blinded trials (based on critical appraisal criteria for Review Question 2); *Itoh \& Katsumi (2005) and *Itoh et al. (2007) each had two eligible sham groups; in both of these trials one group had a non-penetrating (NP) sham and the other had a penetrating (P) sham (labelled accordingly in the first column of the table). ^Itoh \& Katsumi (2005) only reported the number of participants from each group who guessed they were in the active group, therefore, to calculate the Bl it was conservatively assumed that the remaining participants guessed they were in the sham group (i.e. no DK responses). 


\section{Table 5 (on next page)}

Hypothesised effects of intervention belief on pain for group comparisons where the Blinding Index (BI) could be calculated ( $\mathrm{N}=12$ ) [adapted from Bang et al. (2010)]

No. Scenario Number; AG Active Group; SG Sham Group; N Number of group comparisons; n number of participants. 
Table 5 Hypothesised effects of intervention belief on pain for group comparisons where the Blinding Index (BI) could be calculated ( $N=12$ group comparisons) [adapted from Bang et al. (2010)]

\begin{tabular}{|c|c|c|c|c|c|c|c|}
\hline \multirow[t]{2}{*}{ No. } & \multirow[t]{2}{*}{ AG beliefs } & \multirow[t]{2}{*}{ SG beliefs } & \multicolumn{3}{|c|}{$\begin{array}{l}\text { Hypothesised moderation effect of } \\
\text { intervention belief on pain outcomes }\end{array}$} & \multirow[t]{2}{*}{$N(\%)$} & \multirow[t]{2}{*}{$n(\%)$} \\
\hline & & & AG & SG & Between group & & \\
\hline 1 & Incorrect (sham) & Incorrect (active) & $\downarrow$ & $\uparrow$ & Large; in favour of SG & $0(0)$ & $0(0)$ \\
\hline 2 & Random & Incorrect (active) & - & $\uparrow$ & Small; in favour of SG & $0(0)$ & $0(0)$ \\
\hline 3 & Incorrect (sham) & Random & $\downarrow$ & - & Small; in favour of SG & $0(0)$ & $0(0)$ \\
\hline 4 & Incorrect (sham) & Correct (sham) & $\downarrow$ & $\downarrow$ & None (reduced in both groups) & $0(0)$ & $0(0)$ \\
\hline 5 & Random & Random & - & - & None & $0(0)$ & $0(0)$ \\
\hline 6 & Correct (active) & Incorrect (active) & $\uparrow$ & $\uparrow$ & None (inflated in both groups) & $8(67)$ & $145(58)$ \\
\hline 7 & Correct (active) & Random & $\uparrow$ & - & Small; in favour of $A G$ & $3(25)$ & $72(29)$ \\
\hline 8 & Random & Correct (sham) & - & $\downarrow$ & Small; in favour of $A G$ & $0(0)$ & $0(0)$ \\
\hline 9 & Correct (active) & Correct (sham) & $\uparrow$ & $\downarrow$ & Large; in favour of $A G$ & $1(8)$ & $31(13)$ \\
\hline
\end{tabular}

No. Scenario Number; AG Active Group; SG Sham Group; N Number of group comparisons; $\mathbf{n}$ rumber of participants.

5 


\section{Figure 1 (on next page)}

Preferred Reporting Items for Systematic Reviews and Meta-Analyses (PRISMA) flow diagram ( www.prisma-statement.org )

*Processes performed by two independent reviewers. 


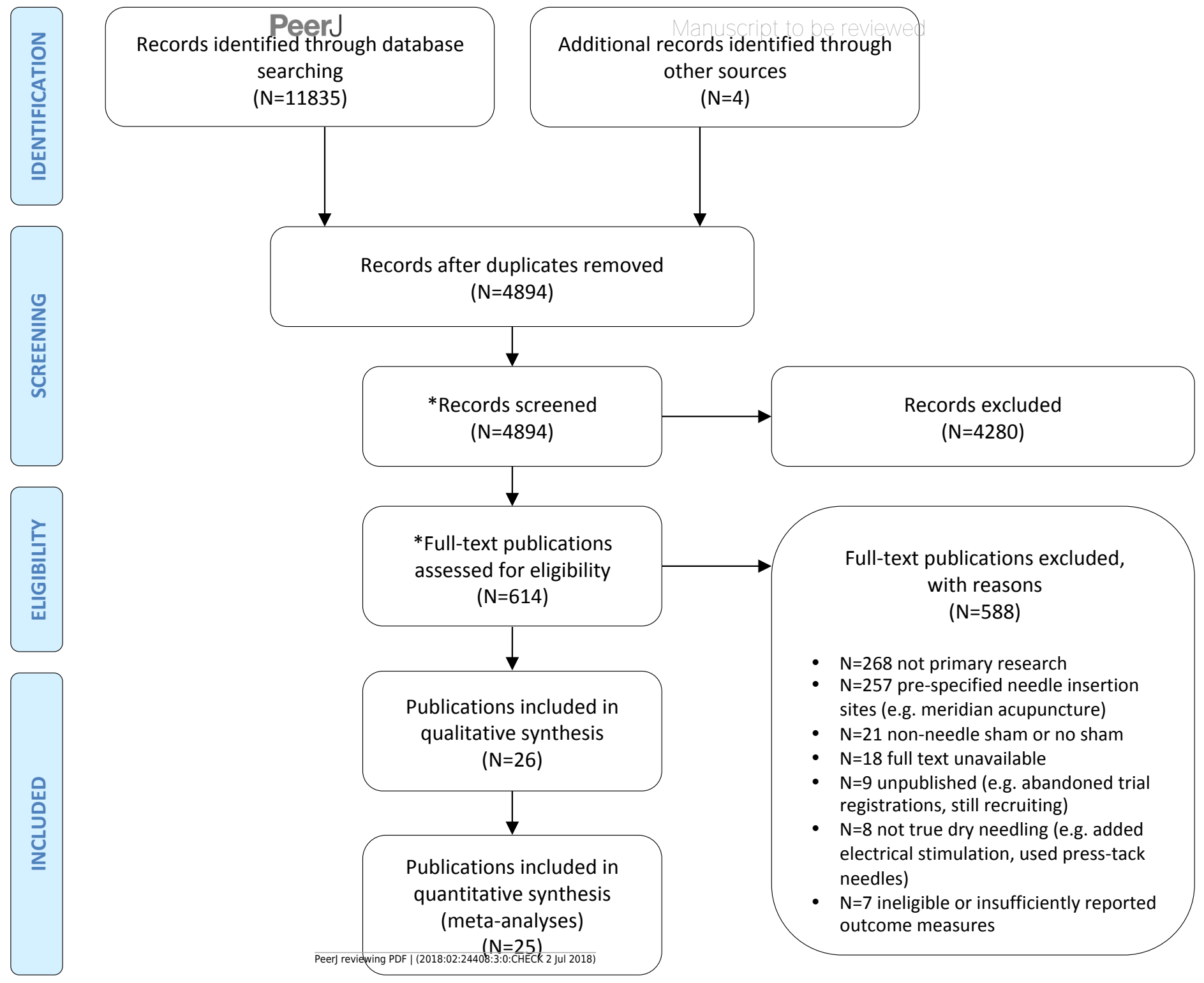


Figure 2 (on next page)

Contour-enhanced funnel plots for pain outcomes in dry needling trials.

(A) Funnel plot for Review Question 1 (blinding effectiveness): time-point closest to when blinding was assessed. (B, C, D) Funnel plots for Review Question 2 (blinding adequacy) [(B) Pain assessments immediately after first/only intervention; (C) Short-term pain assessments; (D) Long-term pain assessments]. 

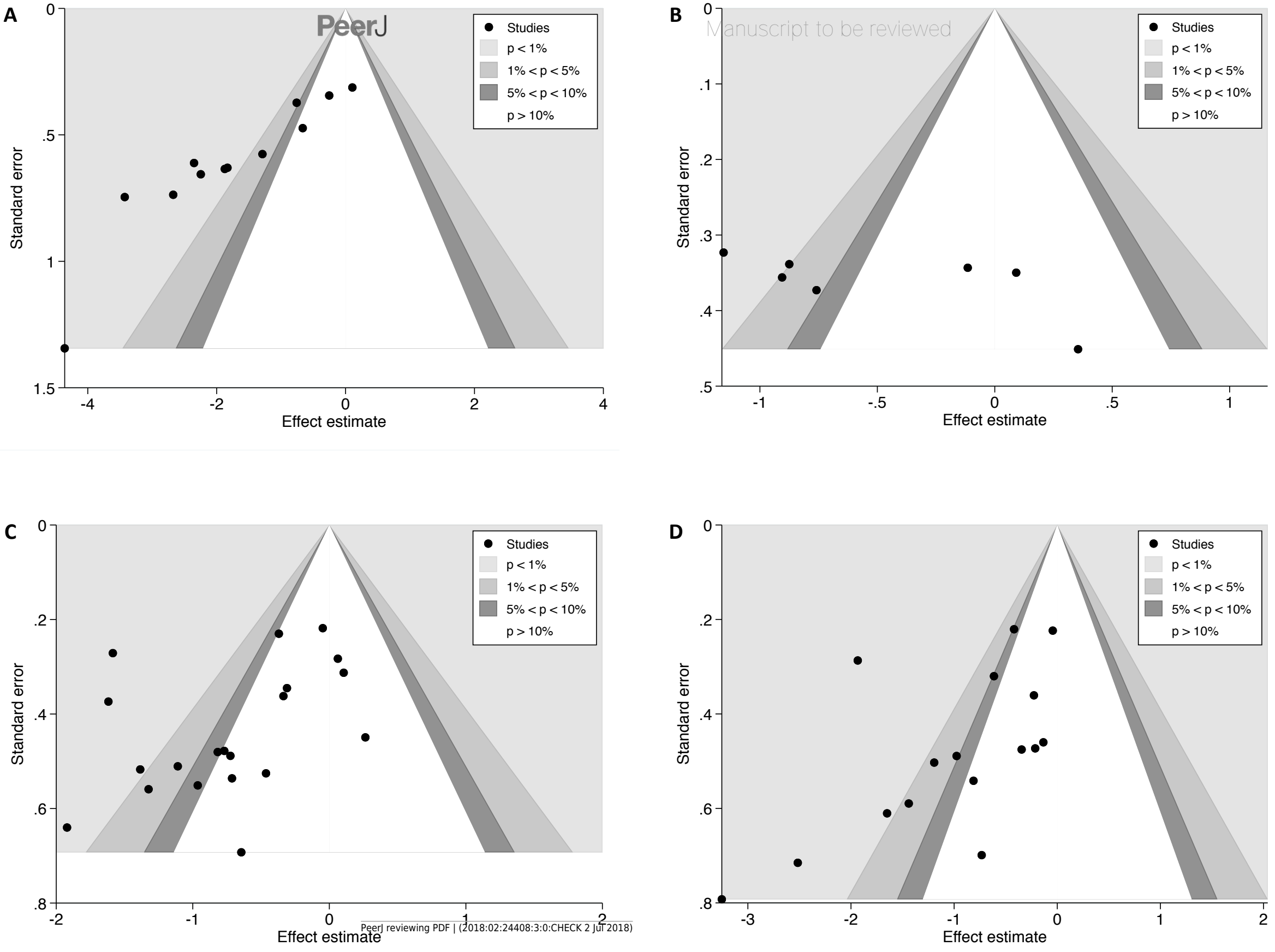
Figure 3 (on next page)

Bubble plot (meta-regression) of the influence of the summary BI (blinding effectiveness) on between-group effect size (pain) for pain assessments closest to the time point blinding was assessed ( $\mathrm{N}=12$ group comparisons).

Each bubble represents one group comparison, and the size of each bubble is proportional to weight (inverse variance). Negative values for SMD are in favour of active dry needling. SMD Standardised Mean Difference (effect size); BI Blinding Index. 


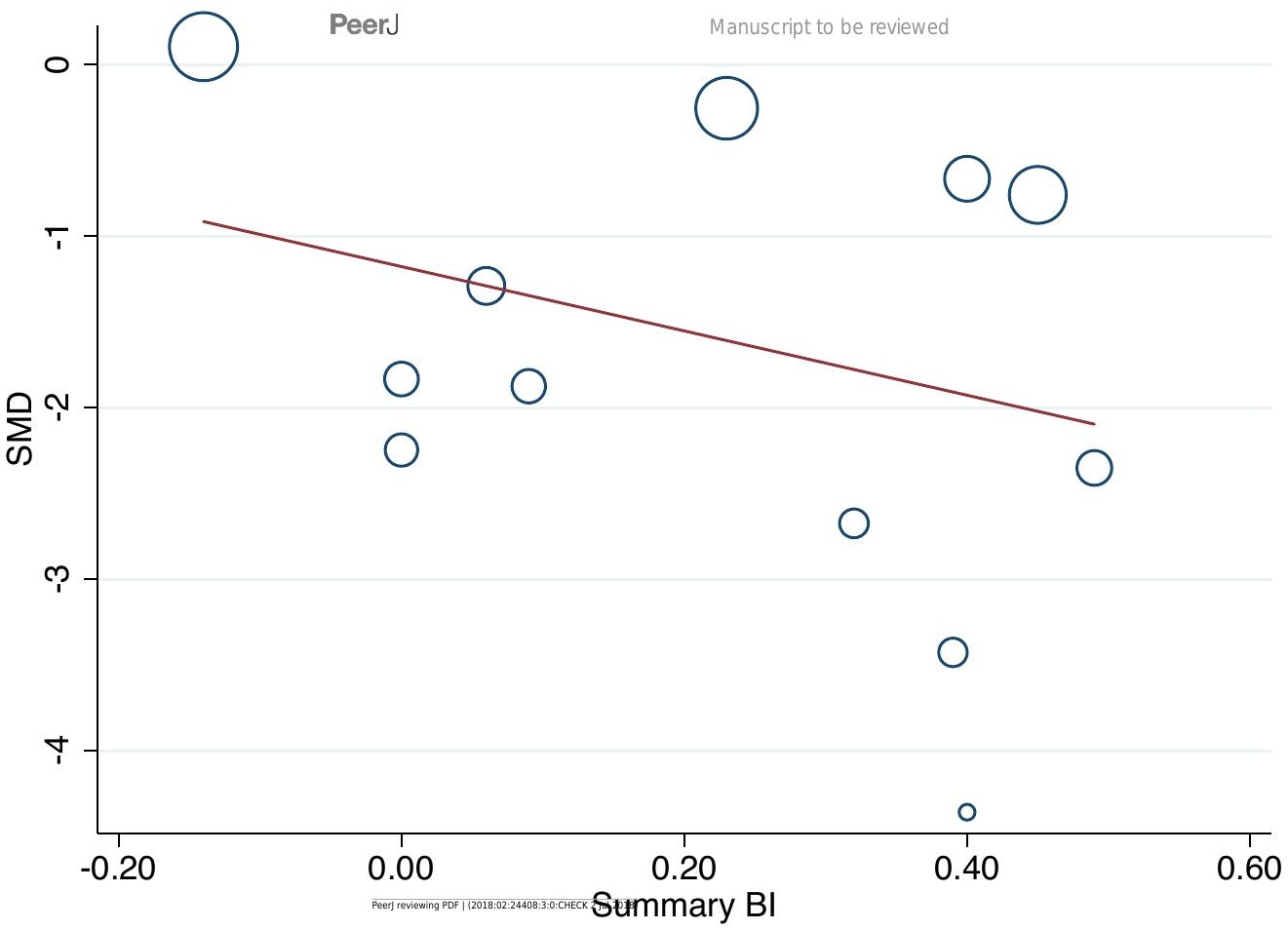




\section{Figure 4 (on next page)}

Forest plot of pooled between-group effect sizes (pain) based on blinding adequacy, for pain assessments immediately after the first/only intervention ( $<24$ hours; $N=7$ group comparisons). 
Adequate

Inoue 2006

Subtotal $(\mathrm{I}$-squared $=. \%, \mathrm{p}=$.

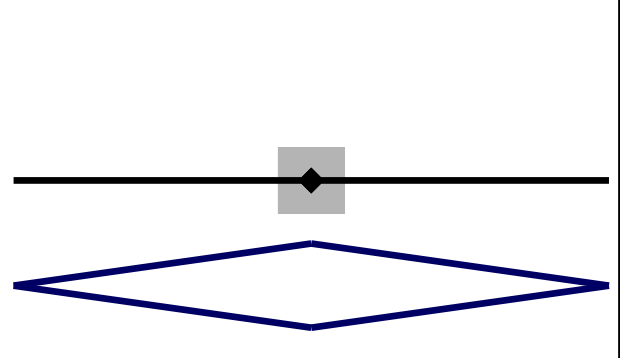

$-0.76(-1.49,-0.03) 100.00$

$-0.76(-1.49,-0.03) 100.00$

Inadequate

Espejo-Antunez 2014

Garcia-Gallego 2011

McMillan 1997

Nabeta 2002

Tekin 2013

Tsai 2010

Subtotal $(\mathrm{I}$-squared $=65.1 \%, p=0.014)$

$-1.15(-1.79,-0.52) 17.87$

$0.09(-0.59,0.78) \quad 16.98$

$0.35(-0.53,1.24) \quad 13.84$

$-0.12(-0.79,0.56) \quad 17.19$

$-0.88(-1.54,-0.21) 17.35$

$-0.91(-1.60,-0.21) 16.77$

$-0.47(-0.95,0.02) \quad 100.00$ 


\section{Figure 5(on next page)}

Forest plot of pooled between-group effect sizes (pain) based on blinding adequacy, for pain assessments in the short-term ( 24 hours to one month; $\mathrm{N}=20$ group comparisons).

Note: Itoh \& Katsumi (2005) and Itoh et al. (2007) each had two eligible sham groups; in both of these trials one group had a non-penetrating (NP) sham and the other had a penetrating (P) sham (labelled accordingly in the figure). 
Adequate

Cotchett 2014

Itoh 2005 (NP)

Itoh $2005(P)$

Subtotal $(\mathrm{I}$-squared $=41.6 \%, p=0.181$ )

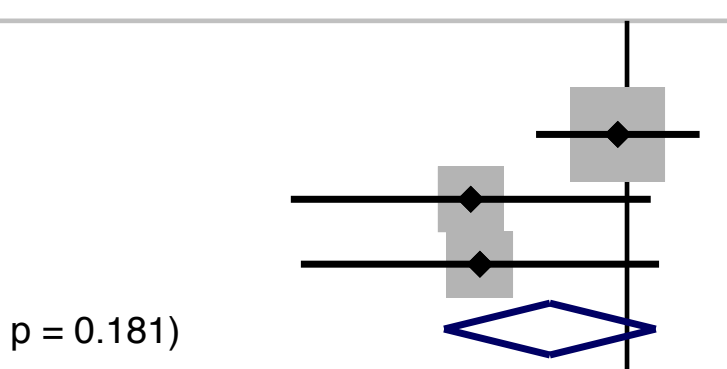

$-0.05(-0.48,0.38)$

52.31

$-0.82(-1.76,0.12)$

23.77

$-0.77(-1.71,0.17)$

23.93

$-0.40(-0.96,0.15)$

100.00

Inadequate

Diracoglu 2012

Itoh 2004

Itoh 2006a

Itoh $2006 \mathrm{~b}$

Itoh 2007 (NP)

Itoh 2007 (P)

Itoh 2008

Itoh 2012

Itoh 2014

Katsumi 2004

Mayoral 2013

McMillan 1997

Myburgh 2012

Nabeta 2002

Pecos-Martin 2015

Tekin 2013

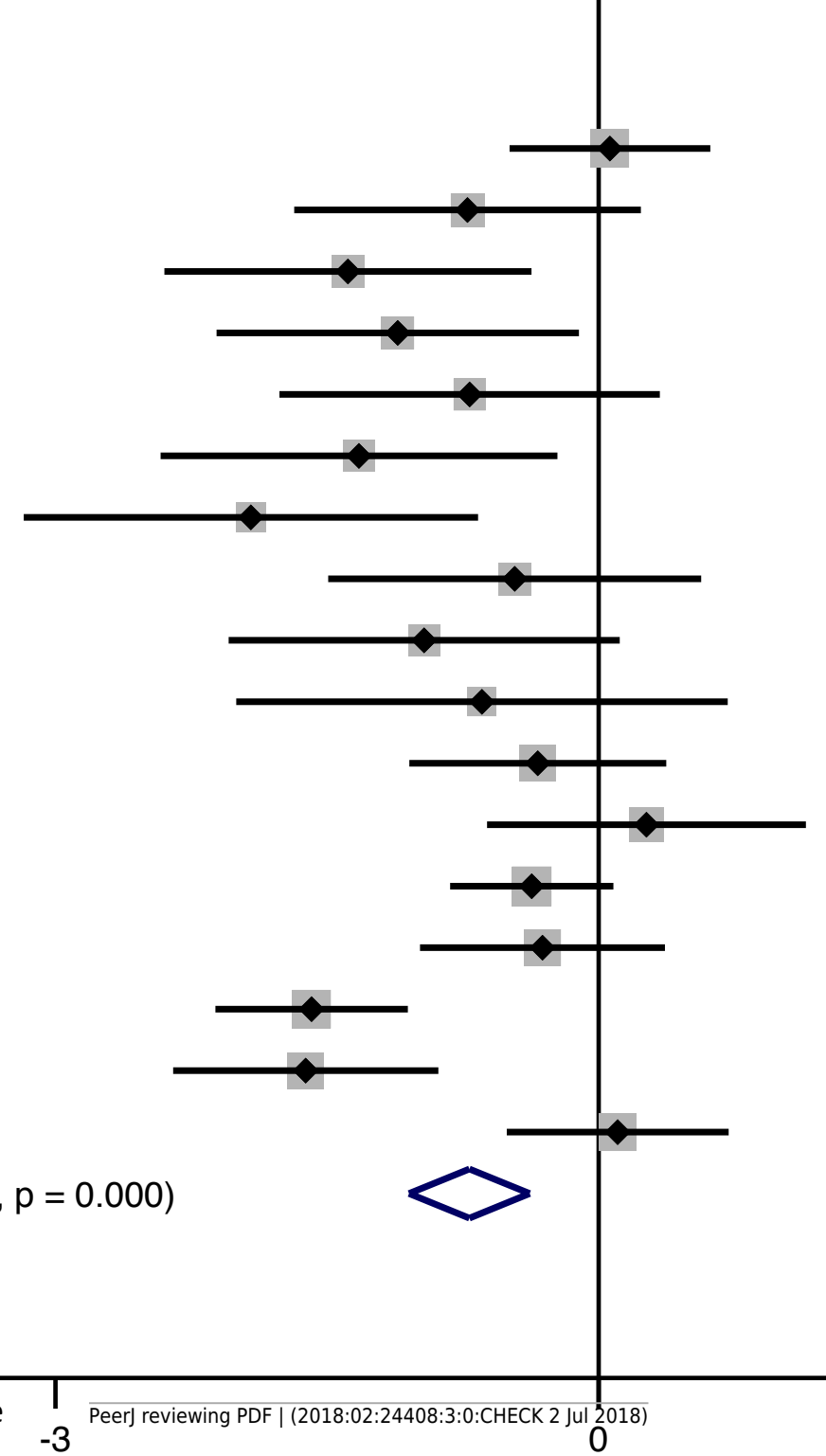

$0.06(-0.49,0.62)$

7.65

$-0.72(-1.68,0.23)$

5.39

$-1.38(-2.40,-0.37)$

5.11

$-1.11(-2.11,-0.11)$

5.17

$-0.71(-1.76,0.34)$

4.94

$-1.32(-2.42,-0.23)$

4.73

$-1.92(-3.18,-0.67)$

$-0.46(-1.49,0.57)$

5.03

$-0.96(-2.04,0.12)$

4.80

$-0.64(-2.00,0.71)$

3.72

$-0.34(-1.05,0.37)$

6.74

$0.26(-0.62,1.14)$

5.78

$-0.37(-0.82,0.08)$

8.24

$-0.31(-0.99,0.37) \quad 6.93$

$-1.59(-2.12,-1.05) \quad 7.78$

$-1.62(-2.35,-0.89) \quad 6.60$

Tough 2009

$0.11(-0.51,0.72)$

7.30

Subtotal $(\mathrm{I}$-squared $=65.8 \%, p=0.000$

$-0.71(-1.05,-0.38)$

100.00 


\section{Figure 6 (on next page)}

Forest plot of pooled between-group effect sizes (pain) based on blinding adequacy, for pain assessments in the long-term (one to six months; $\mathrm{N}=16$ group comparisons).

Note: Itoh \& Katsumi (2005) and Itoh et al. (2007) each had two eligible sham groups; in both of these trials one group had a non-penetrating (NP) sham and the other had a penetrating (P) sham (labelled accordingly in the figure). 


\section{Adequate}

Cotchett 2014

Itoh 2005 (NP)

Itoh $2005(P)$

Sterling 2015

Subtotal $($ I-squared $=17.5 \%, p=0.303$ )

Inadequate

Itoh 2004

Itoh 2006a

Itoh $2006 b$

Itoh 2007 (NP)

Itoh $2007(P)$

Itoh 2008

Itoh 2012

Itoh 2014

Katsumi 2004

Mayoral 2013

Pecos-Martin 2015

Tough 2009

Subtotal $(\mathrm{I}$-squared $=69.2 \%, p=0.000$ )

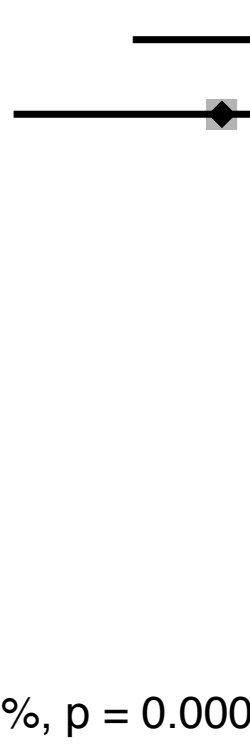

$\begin{array}{ll}-0.42(-0.85,0.01) & 39.33 \\ -0.98(-1.93,-0.02) & 10.42 \\ -0.13(-1.04,0.77) & 11.65 \\ -0.04(-0.48,0.39) & 38.60 \\ -0.30(-0.62,0.02) & 100.00\end{array}$

$-0.21(-1.14,0.71) \quad 8.90$

$-1.19(-2.18,-0.21) \quad 8.55$

$-0.35(-1.28,0.59) \quad 8.87$

$-2.52(-3.92,-1.11) \quad 6.35$

-3.25 (-4.81, -1.70) 5.69

$-0.81(-1.87,0.25) \quad 8.11$

$-1.65(-2.85,-0.45) \quad 7.37$

$-1.44(-2.60,-0.28) \quad 7.59$

$-0.73(-2.10,0.64) \quad 6.50$

$-0.23(-0.93,0.48) \quad 10.24$

-1.93 (-2.50, -1.37) 11.09

$-0.61(-1.24,0.01) \quad 10.72$

$-1.14(-1.64,-0.65) \quad 100.00$ 